\title{
STREAM CLASSIFICATION TOOL USER MANUAL: FOR USE IN APPLICATIONS IN HYDROPOWER-RELATED ENVIRONMENTAL MITIGATION
}

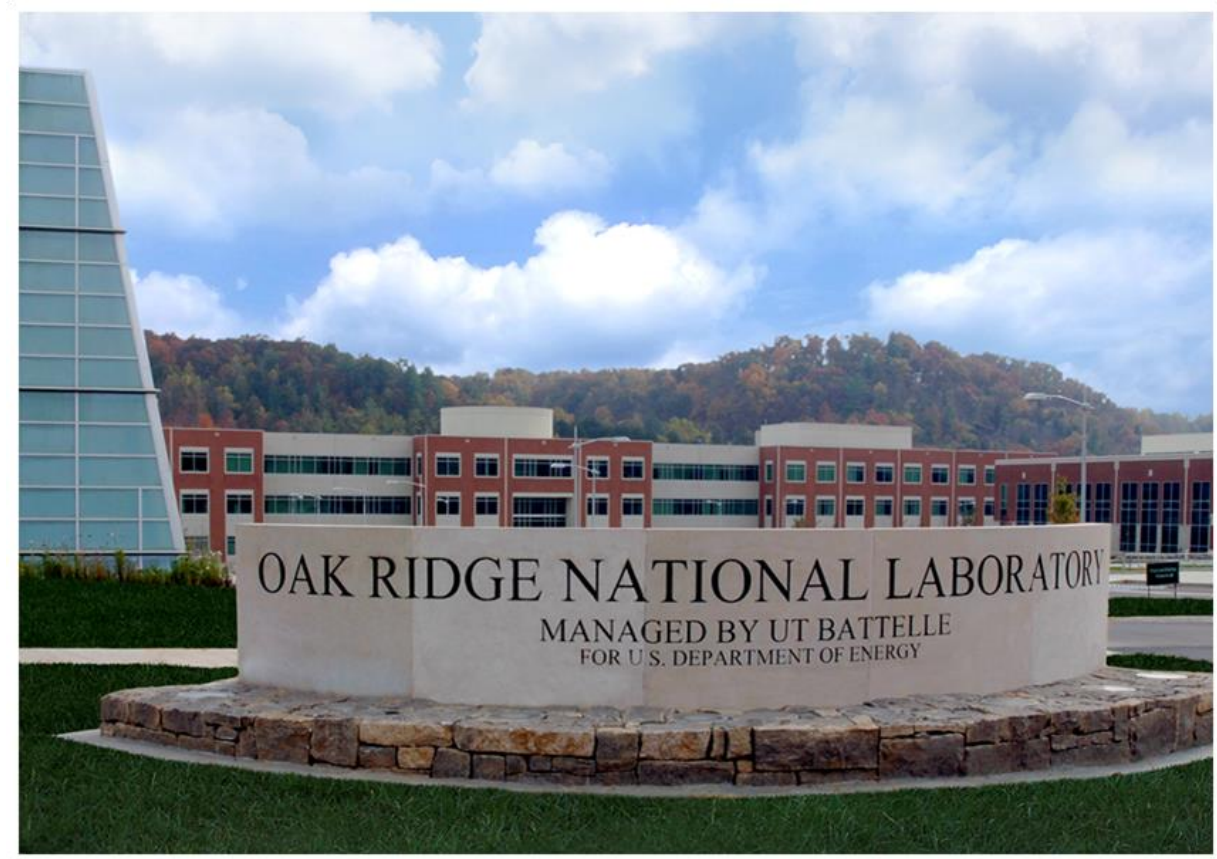

Ryan A. McManamay Matthew J. Troia Christopher R. DeRolph Nicole M. Samu

January 2016 


\title{
DOCUMENT AVAILABILITY
}

Reports produced after January 1, 1996, are generally available free via US Department of Energy (DOE) SciTech Connect.

Website http://www.osti.gov/scitech/

Reports produced before January 1, 1996, may be purchased by members of the public from the following source:

\author{
National Technical Information Service \\ 5285 Port Royal Road \\ Springfield, VA 22161 \\ Telephone 703-605-6000 (1-800-553-6847) \\ TDD 703-487-4639 \\ Fax 703-605-6900 \\ E-mail info@ntis.gov \\ Website http://www.ntis.gov/help/ordermethods.aspx
}

Reports are available to DOE employees, DOE contractors, Energy Technology Data Exchange representatives, and International Nuclear Information System representatives from the following source:

Office of Scientific and Technical Information

PO Box 62

Oak Ridge, TN 37831

Telephone 865-576-8401

Fax 865-576-5728

E-mail reports@osti.gov

Website http://www.osti.gov/contact.html

This report was prepared as an account of work sponsored by an agency of the United States Government. Neither the United States Government nor any agency thereof, nor any of their employees, makes any warranty, express or implied, or assumes any legal liability or responsibility for the accuracy, completeness, or usefulness of any information, apparatus, product, or process disclosed, or represents that its use would not infringe privately owned rights. Reference herein to any specific commercial product, process, or service by trade name, trademark, manufacturer, or otherwise, does not necessarily constitute or imply its endorsement, recommendation, or favoring by the United States Government or any agency thereof. The views and opinions of authors expressed herein do not necessarily state or reflect those of the United States Government or any agency thereof. 
Environmental Sciences Division

STREAM CLASSIFICATION TOOL USER MANUAL: FOR USE IN APPLICATIONS IN HYDROPOWER-RELATED ENVIRONMENTAL MITIGATION

\author{
Ryan A. McManamay \\ Matthew J. Troia \\ Christopher R. DeRolph \\ Nicole M. Samu
}

Date Published: January 2016

\author{
Prepared by \\ OAK RIDGE NATIONAL LABORATORY \\ Oak Ridge, TN 37831-6283 \\ managed by \\ UT-BATTELLE, LLC \\ for the \\ US DEPARTMENT OF ENERGY \\ under contract DE-AC05-00OR22725
}





\section{CONTENTS}

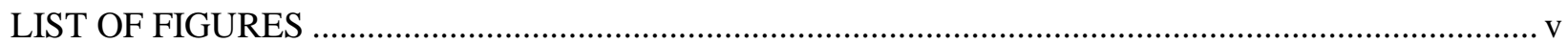

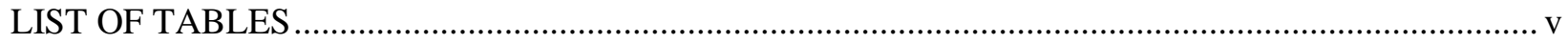

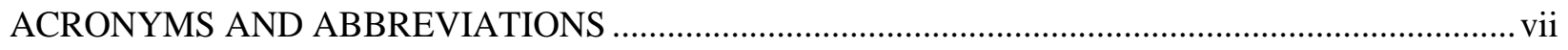

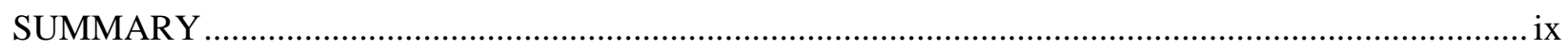

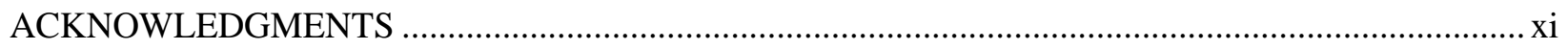

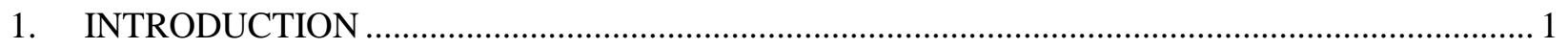

2. A STREAM CLASSIFICATION TOOL FOR THE EASTERN UNITED STATES ...................... 5

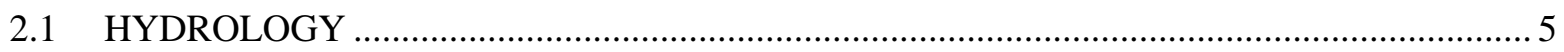

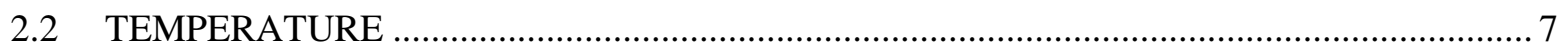

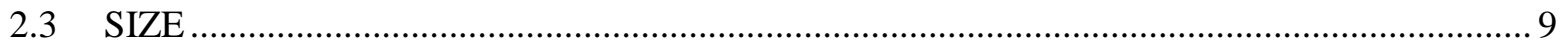

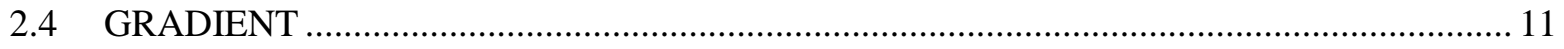

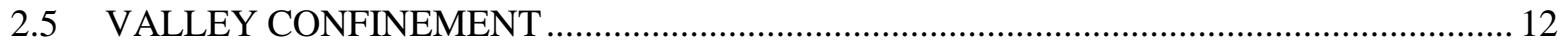

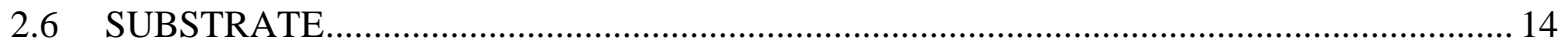

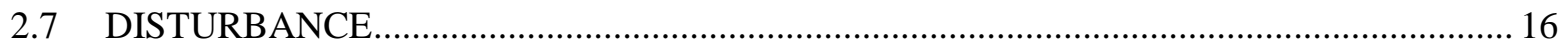

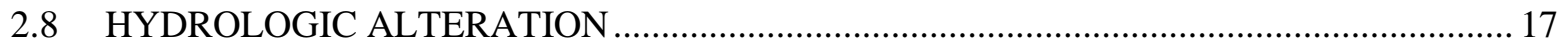

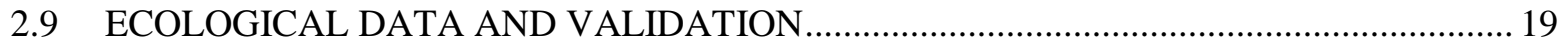

3. APPLICATION OF SCT TO ENVIRONMENTAL MITIGATION FOR HYDROPOWER

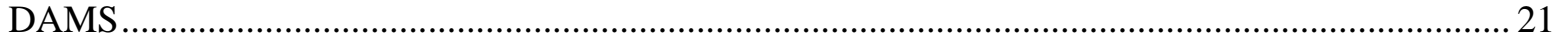

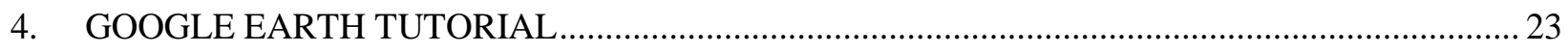

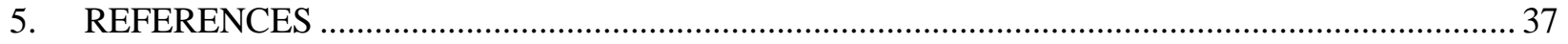




\section{LIST OF FIGURES}

Figure 1. Layers within the Stream Classification System. .......................................................... 3

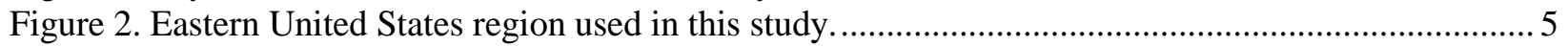

Figure 3. Development of hydrologic classes in stream reaches. ....................................................... 6

Figure 4. Example of hydrologic classes within the Mid-Atlantic Region........................................... 7

Figure 5. Temperature monitoring stations assembled for temperature classification (A), and the variation in summer averages (July, August mean) across the region (B).................................... 8

Figure 6. Example of temperature classes mapped to stream reaches within the South Atlantic

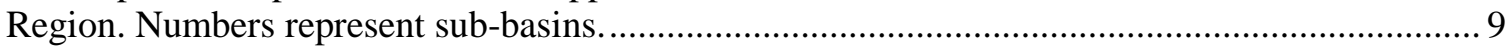

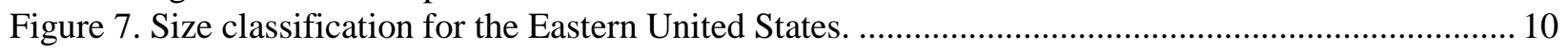

Figure 8. Example of size classification in stream reaches for the Northeast Region. .............................. 11

Figure 9. Major breaks in gradient proposed by Rosgen (1994) and gradient classes developed for

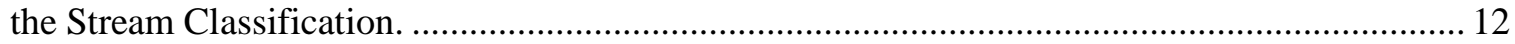

Figure 10. An example of gradient classes mapped to stream reaches in the Great Lakes Region........... 12

Figure 11. Valley bottoms delineated for the entire region (A)...................................................... 13

Figure 12. An exmaple of valley confinement classes for the Ohio Region.......................................... 14

Figure 13. Reference sites $(n=460)$ were substrate conditions were assessed $(A)$, and predicted mean substrate diameter based on random forest models (B) ................................................. 15

Figure 14. Landscape condition of stream reaches as measured by the National Fish Habitat

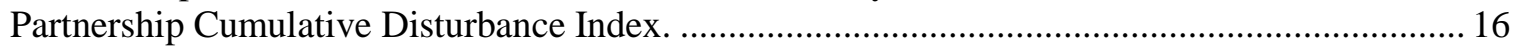

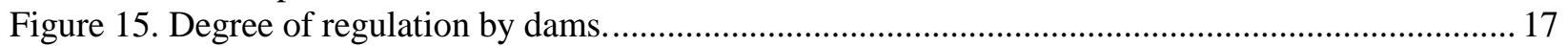

Figure 16. Method of calculating and mapping hydrologic alteration in stream reaches......................... 18

Figure 17. Reference and non-reference gages used in calculating the Hydrologic Alteration

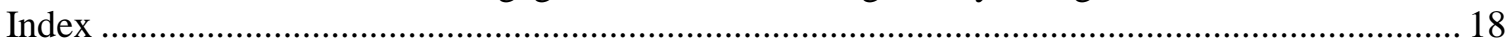

Figure 18. Fish community sites (red dots) and individual fish species records (black dots) in the

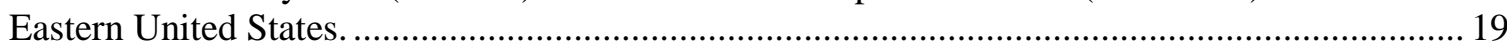

Figure 19. Conceptual model illustrating the utility of the Stream Classification Tool in

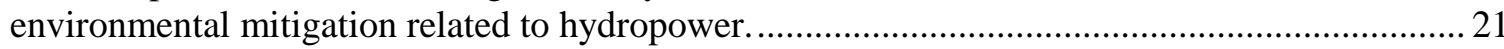

\section{LIST OF TABLES}

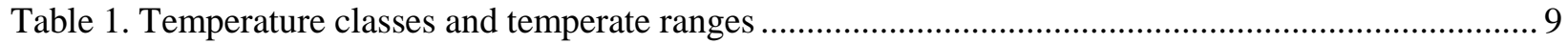

Table 2. Substrate classes and minimum and maximum diameters ....................................................... 16 


\section{ACRONYMS AND ABBREVIATIONS}

$\begin{array}{ll}\text { DEM } & \text { Digital Elevation Model } \\ \text { DOR } & \text { Degree of Regulation } \\ \text { EPA } & \text { U.S. Environmental Protection Agency } \\ \text { NFHP } & \text { National Fish Habitat Partnership } \\ \text { NHD } & \text { National Hydrography Dataset } \\ \text { SCT } & \text { Stream Classification Tool } \\ \text { SSD } & \text { sum of squared distance } \\ \text { USGS } & \text { U.S. Geological Survey } \\ \text { VCA } & \text { Valley Confinement Algorithm }\end{array}$




\section{SUMMARY}

Stream classifications are an inventory of different types of streams. Classifications help us explore similarities and differences among different types of streams, make inferences regarding stream ecosystem behavior, and communicate the complexities of ecosystems. We developed a nested, layered, and spatially contiguous stream classification to characterize the biophysical settings of stream reaches within the Eastern United States ( 900,000 reaches). The classification is composed of five natural characteristics (hydrology, temperature, size, confinement, and substrate) along with several disturbance regime layers, and each was selected because of their relevance to hydropower mitigation. We developed the classification at the stream reach level using the National Hydrography Dataset Plus Version 1 (1:100k scale). The stream classification is useful to environmental mitigation for hydropower dams in multiple ways. First, it creates efficiency in the regulatory process by creating an objective and data-rich means to address meaningful mitigation actions. Secondly, the Stream Classification Tool (SCT) addresses data gaps as it quickly provides an inventory of hydrology, temperature, morphology, and ecological communities for the immediate project area, but also surrounding streams. This includes identifying potential reference streams as those that are proximate to the hydropower facility and that fall within the same class. These streams can potentially be used to identify ideal environmental conditions or identify desired ecological communities. In doing so, the SCT provides some context for how streams may function and how they respond to dam regulation, and it provides an overview of specific mitigation needs. In this document, we describe the methodology in developing each stream classification layer and we provide a tutorial to guide applications of the classification (and associated data) in regulatory settings, such as hydropower (re)licensing. 


\section{ACKNOWLEDGMENTS}

This study was funded by the Department of Energy Water Power Program. We thank The Nature Conservancy Eastern Regional Office, specifically Arlene Olivero, Analie Barnett, and Mark Anderson, with assistance in developing geospatial layers. Thanks to Brennan Smith, Shelaine Hetrick, and ShihChieh Kao for their assistance in supporting and reviewing this work. Tim Welch served as the sponsor for this work and provided helpful insights into the application of the Stream Classification Tool. 


\section{INTRODUCTION}

Classification systems have a long history in stream ecology (Horton 1945; Strahler, 1957; Pennak 1971; Rosgen 1994; Frissel et al. 1986). Classifications help us explore similarities and differences among different types of streams, make inferences regarding stream ecosystem behavior, and communicate the complexities of ecosystem function (Sokal 1974). While classifications aid in understanding fundamental differences among streams, they also have many applied outcomes such as grouping sites with similar character (Frimpong and Angermeier, 2010), stratifying analyses for monitoring and/or experimentation (Wolock et al. 2004), prioritizing mitigation or aquatic conservation (Snelder et al. 2007), and generalizing ecological responses to disturbances (Bailey 1983).

At a basic level, stream classifications are an inventory of different types of streams. One of the simplest examples is that of Stream Orders (Strahler 1957) where the smallest headwater systems are termed firstorder streams, and where two first-order streams join, a second-order stream is formed; where two second-order streams join, a third-order stream is formed, and so on. Although very simple, this is an important classification as it relates to stream size, drainage area, channel width, power, and the structure of ecological communities. Another example is the hierarchical framework for stream classification proposed by Frissel et al. (1986) were the smallest habitats, microhabitats $\left(10^{-1} \mathrm{~m}\right)$, are nested within mesohabitats (pools, riffles, $10^{0} \mathrm{~m}$ ), which are nested within reaches $\left(10^{1} \mathrm{~m}\right)$, and reaches within segments $\left(10^{2} \mathrm{~m}\right)$, and segments within watersheds $\left(10^{3} \mathrm{~m}\right)$. Defining stream habitats according to scale ensures analyses can be placed within appropriate contexts and aids in understanding how processes at larger scales influence the structure and organization of habitats at smaller scales. Many classification systems have been used in stream management and developing monitoring strategies (Omernick 1986;

Rosgen 1994; Wolock et al. 2004). For example, the Rosgen classification has been widely applied in the US as a detailed template to guide stream restoration practices. For example, stream channel classes differ in entrenchment ratio, width/depth ratio, sinuosity, bed slope, and substrate coarseness. These classes represent expected conditions for the morphological condition of streams; thus, the expected values guide specific restoration practices of impaired systems, such as channel reconfiguration to match sinuosity conditions or placing grade control structures to stabilize systems back to typical bed slopes.

Based on previous classification frameworks, we recognize three properties that ensure successful application of stream classification systems to environmental management: (1) nested structure, (2) layered organization, and (3) spatially contiguous. Nested classification systems refer to spatial designs that are dependent upon scale of observation (e.g., Frissel et al. 1986). For example, at a fine spatial resolution, distinct types of patches of habitat may be apparent, whereas at very coarse scales differences among watersheds become realized. Conducting classifications at a moderately fine resolution, such as that of stream reaches, provides a framework to scale analyses down to the patch level (mesohabitats) but also to scale up to the watershed level. This functionality is provided by the topological connections among stream reaches (provided by the National Hydrography Dataset), as this is a routing mechanism but also a mechanism to accumulate upstream landscape variables. For example, hydrologic classes are created on the basis of climate, topography, and soil variables summarized for the entire drainage upstream of each stream reach.

A layered approach provides that a classification can be made up of one to many habitat constituents (e.g., size, hydrology, temperature) (Figure 1). Thus, the classification can accommodate for the selection of only one or many components that may be relevant to the problem at hand. For example, suppose a region of the U.S. Army Corps of Engineers is conducting a broad analysis of sedimentation in reservoirs for which there is a need to understand the divergent nature of sediment regimes of streams across a region. In this case, temperature would not be relevant, whereas size, gradient, and hydrology would be very important to consider. Hence, approaches that are hierarchical and layered inherently provide for flexible 
complexity, where an investigator has options to select a number of different layers and/or different numbers of groups within layers. In contrast, cocktail approaches lump multiple layers and selected groups into a single classification framework. For example, Ecoregions represent areas of unique climate, hydrology, geomorphology, topography, land use, and ecological communities (Omerick 1987). In the case of Ecoregions, one cannot examine patterns in hydrology separate from topography or land use. While cocktail approaches are convenient in that they consolidate multiple layers of information into a simple framework, they lack mechanistic associations between the distribution of organisms and the habitats they require, but also they lack an ability to link unique ecosystem responses to disturbance regimes. This becomes extremely important when attempting to understand ecosystem responses to disturbance, such as dam regulation. As a hypothetical example, suppose we compare several streams, all of which are below hydropower dams of similar size, capacity, and operation, but occurring in two different ecoregions (e.g., Blue Ridge and Ridge and Valley Ecoregions). Some streams in different Ecoregions have completely different biophysical responses to hydropower (e.g., hydrologic and thermal regime; loss of sensitive species), whereas others share very similar responses. The differences may be due to different individual components (e.g., temperature class) which play varying roles of importance in biophysical responses. For example, a stream with higher, more stable baseflows will respond differently to peaking operations (in terms of hydrology) than a system with less stable, lower baseflows. Likewise, a warm temperature system will respond differently to hypolimnetic releases than a cool temperature system. Because cocktail approaches lump components into one framework, there is no way to separate the relative importance of layers as causal factors that predispose streams to different responses to disturbance.

Another important consideration of classification systems is developing spatially contiguous layers. In many cases, classifications are created by clustering discrete observations. As common examples, hydrologic classifications have been developed by summarizing discharge patterns at stream gaging stations into statistics, which are then used as input to multivariate clustering algorithms (Olden et al. 2012). The result is that hydrologic classes are represented as groups of gaging stations that represent similar patterns in hydrology; however, this leaves large sections of rivers unclassified according to their hydrologic behavior. Predictive models can be developed using climate, landscape, and soil variables and can be used to extrapolate hydrologic classes to ungaged streams (Liermann et al. 2012). In doing so, every stream reach will have a respective hydrologic class to readily inform spatial assessments. 


\section{Stream Classification System}

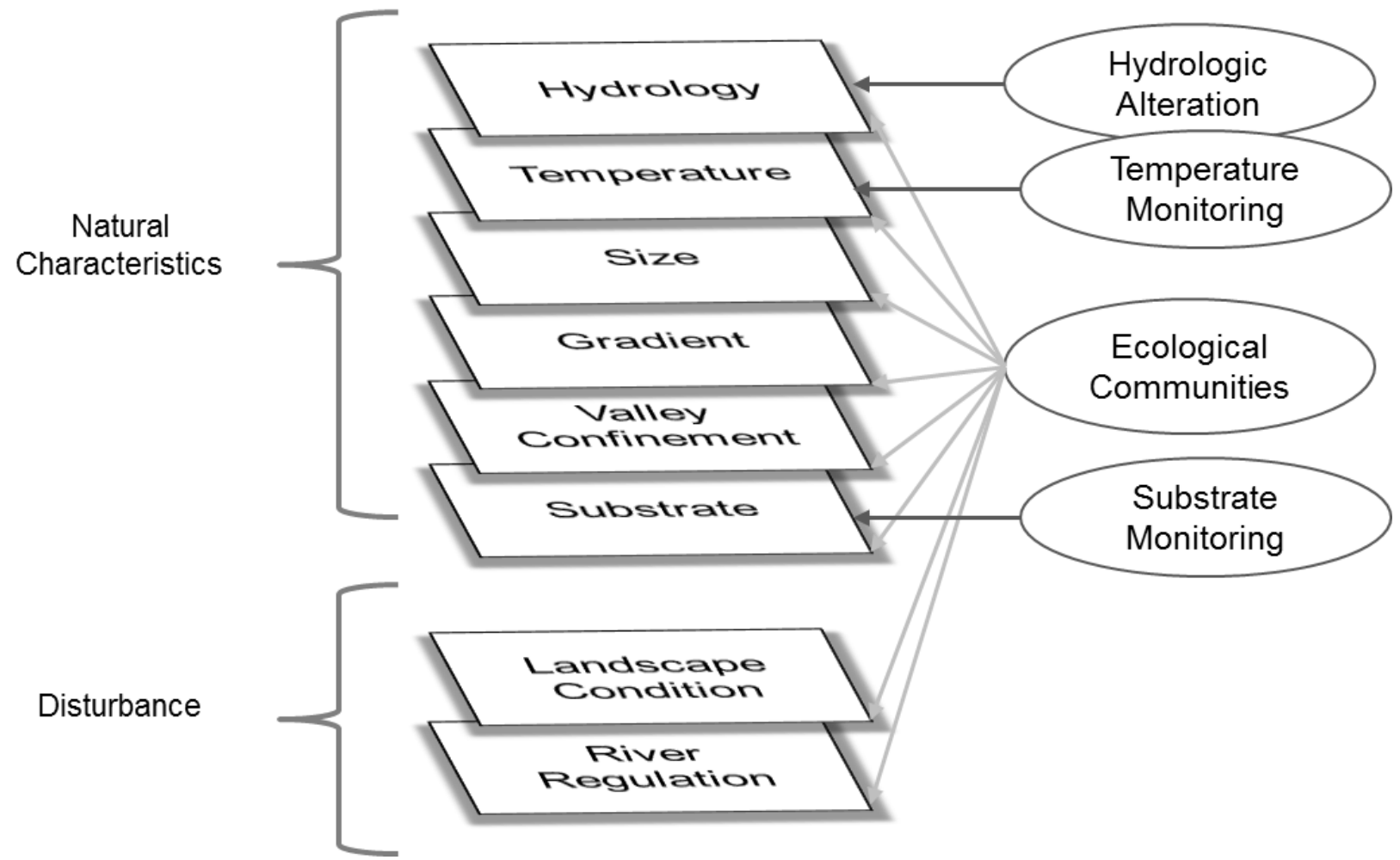

Figure 1. Layers within the Stream Classification System. The classification is made up of eight layers (boxes) representing natural characteristics (6) and two disturbance layers (2). In addition, auxiliary data (ovals) are provided to enrich information gathering. Hydrologic alteration refers to stream gauge monitoring stations that represent reference or hydrologically altered streamflow conditions. Temperature and substrate monitoring stations include locations used to develop the temperature and substrate classifications, respectively, but also locations representing altered regimes. Lastly, ecological community data were assembled to examine patterns in species distributions in relation to stream classes. 


\section{A STREAM CLASSIFICATION TOOL FOR THE EASTERN UNITED STATES}

Given the properties mentioned above, we developed a nested, layered, and spatially contiguous stream classification to characterize the biophysical settings of stream reaches including hydrologic, thermal, geomorphologic, and disturbance within the Eastern United States (Figure 2). The classification was developed at the stream reach level using the National Hydrography Dataset Plus Version 1 (1:100k scale). The classification is composed of five natural characteristics and several disturbance regime layers (Figure 1), and all were selected because of their relevance to hydropower mitigation. Many investigators value having classifications based on natural features because these can be used to relate to ecological patterns or, in cases of mitigation, represent the ideal environmental condition. In the case of layered approach, the strength is that investigators can select layers representing disturbance regimes to represent the current condition of the landscape while being cognizant of natural stream type variation. This is important as different natural stream types may responds differently to disturbance.

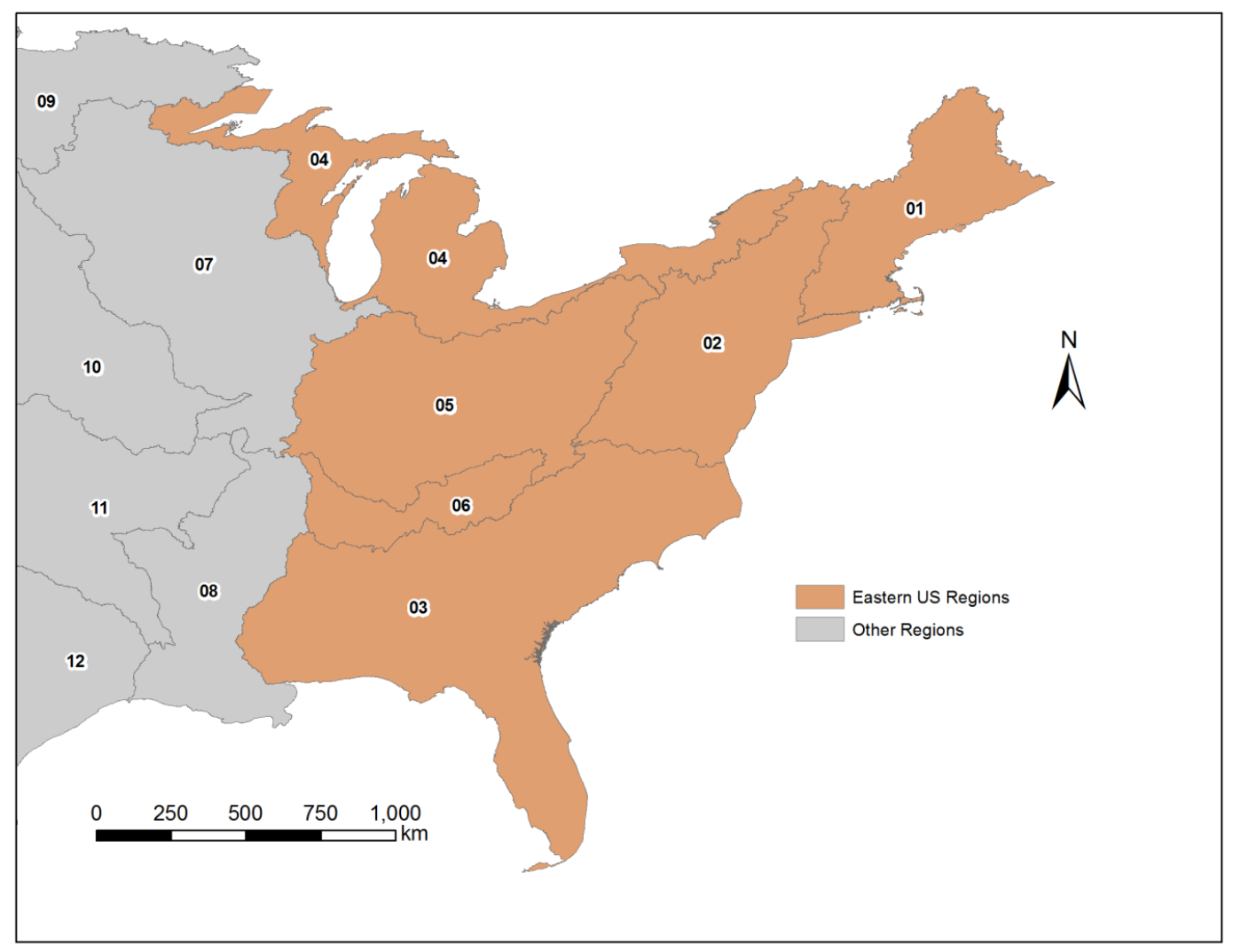

Figure 2. Eastern United States region used in this study.

\subsection{HYDROLOGY}

Hydrologic classes represent groups of streams that share similar characteristics in hydrology. A recent hydrologic classification was completed for the entire United States using > 2600 U.S. Geological Survey (USGS) stream gages representing reference-quality hydrologic information (McManamay et al. 2014) (Figure 3A). Stream gages were clustered using a Bayesian mixed modeling technique based on hydrologic statistics summarizing at least 15 years of discharge data. These classes represent natural variation in hydrology, and classes are not influenced by river size (by standardized magnitude-related statistics). Using 900 gages from the Eastern United States, we developed a random forest model based 
on 67 variables (landscape, climate, topography, and soil attributes). Nine hydrologic classes were represented, and cross-validation classification accuracy was $80.7 \%$. Using the same predictors, we extrapolated hydrologic class membership to all National Hydrography Dataset (NHD) stream reaches in the region (Figure 3B). The most abundant hydrologic types were Perennial Runoff 1 and 2 streams and Stable High Baseflow Streams (Figure 3B, Figure 4).
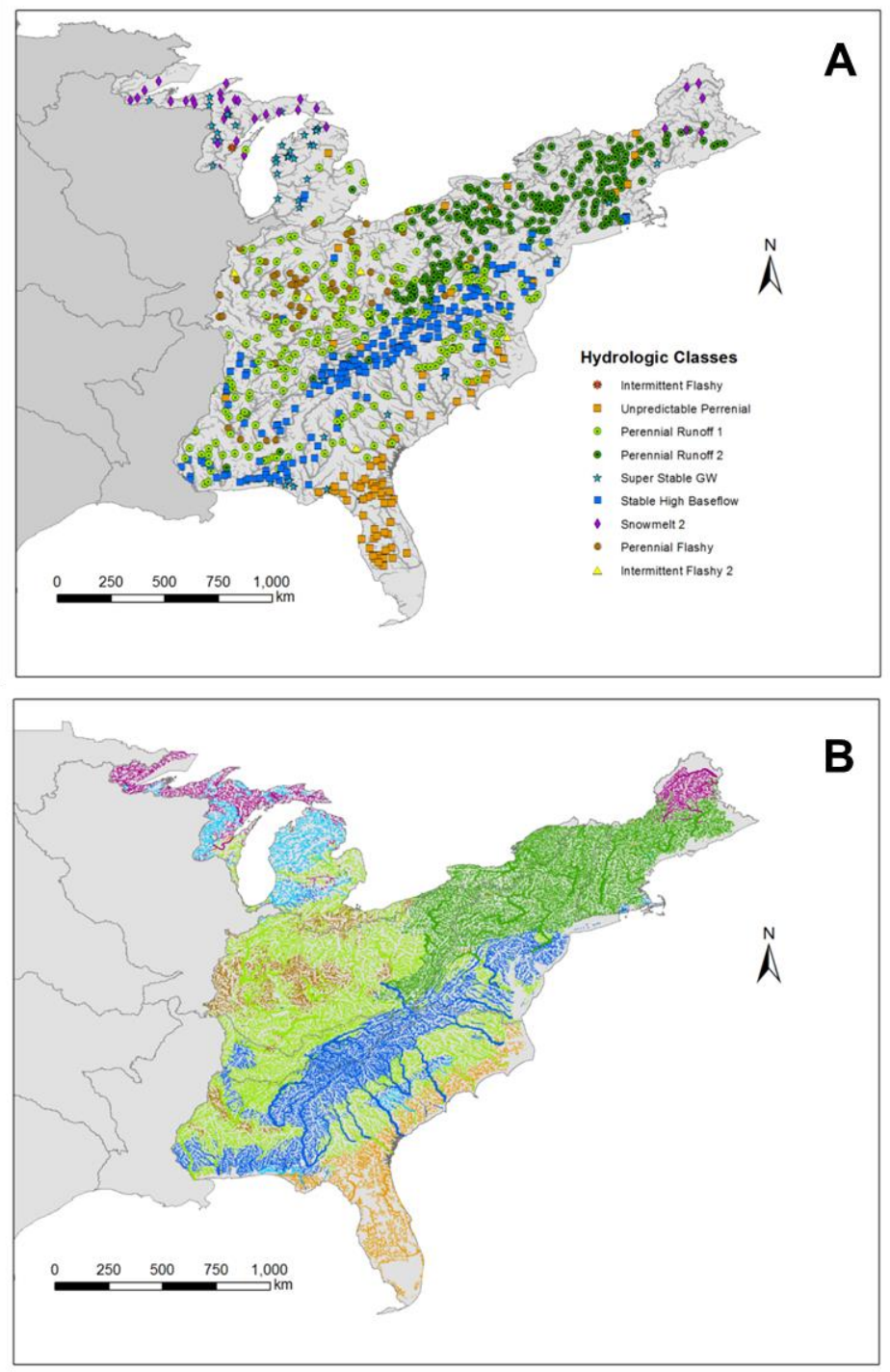

Figure 3. Development of hydrologic classes in stream reaches. Stream gages were clustered into groups according to similaries in hydrology from discharge measurements (A), and then mapped to stream reaches using a predictive model (B). 


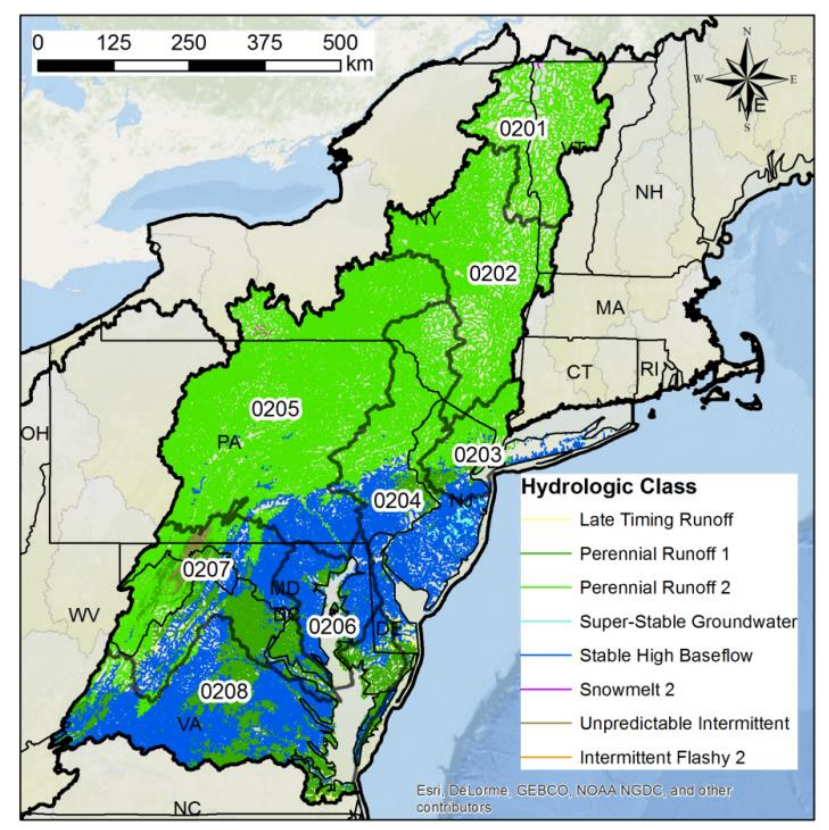

Figure 4. Example of hydrologic classes within the Mid-Atlantic Region.

\subsection{TEMPERATURE}

Relative to other temperature metrics, summer-time temperatures (July-August averages) are likely to be the most influential determinants of ecological communities. We compiled temperature data from multiple sources, including 762 USGS gauges with daily records (Hill et al. 2013) and 1588 individually deployed temperature loggers from federal and state agency personnel (Deweber and Wagner 2014) (Figure 4A). We selected sites that were representative of reference conditions (Figure 5A). Using the same predictor ensemble for hydrology, we developed random forests to predict summer temperatures for 869 reference sites and then extrapolated those values to all NHD stream reaches. Summer time average temperature varied across the Eastern United States (Figure 5B) and within regions (Figure 6). Using estimated summer-time temperature values for all stream reaches in the region, we used a k-means clustering procedure to partition classes. To determine the most parsimonious solution to explain the majority of variation, sum-of-squared-distances (SSDs) within groups were compared to number of clusters (from two to 15 cluster solutions). We determined a breakpoint at five cluster solutions, which approached the minimum SSD but provided a simple solution (Table 1). 

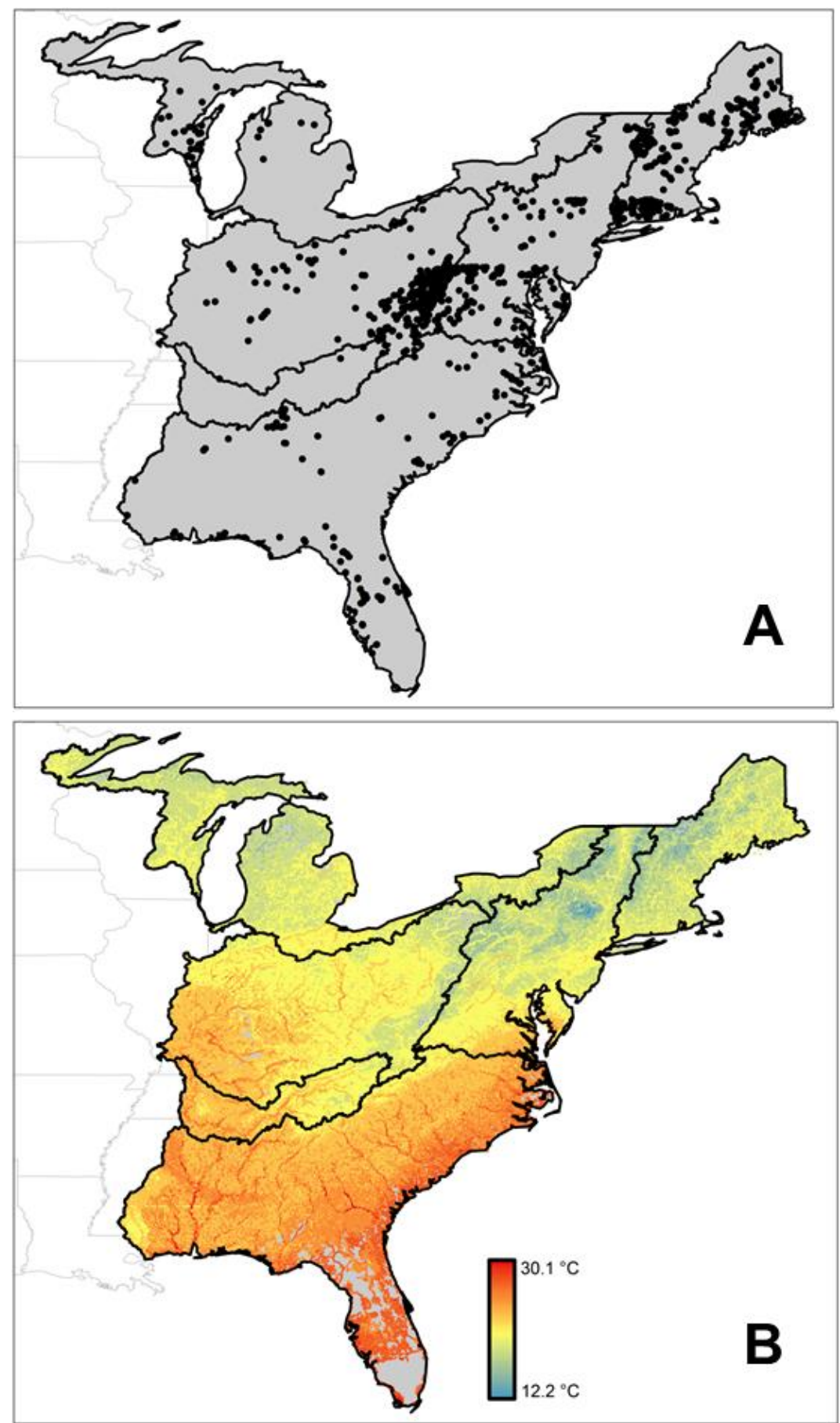

Figure 5. Temperature monitoring stations assembled for temperature classification (A), and the variation in summer averages (July, August mean) across the region (B). 


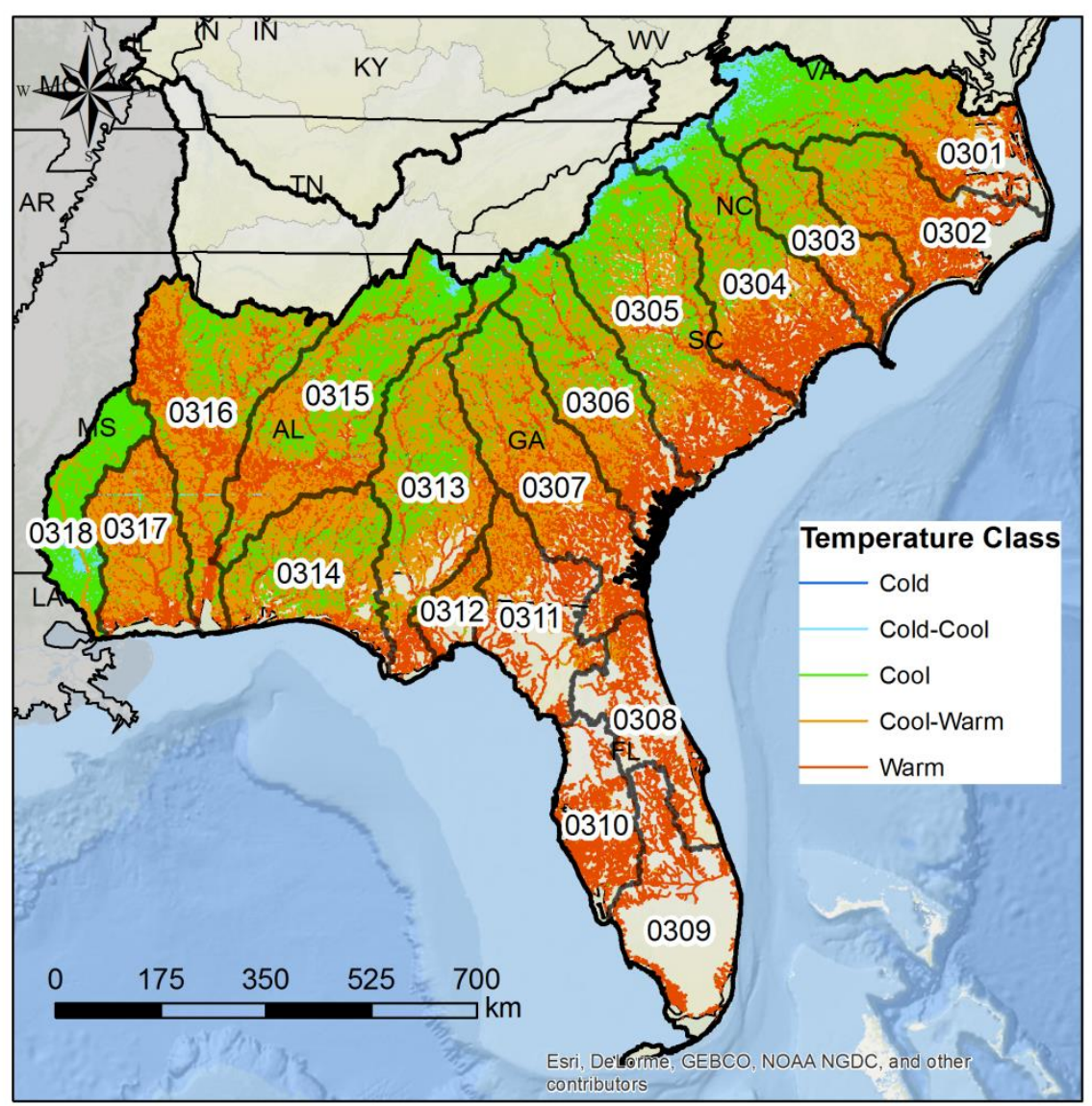

Figure 6. Example of temperature classes mapped to stream reaches within the South Atlantic Region. Numbers represent sub-basins.

Table 1. Temperature classes and temperate ranges

\begin{tabular}{lcc}
\hline \multicolumn{1}{c}{ Temperature Class } & Min Temp $\left({ }^{\circ} \mathbf{C}\right)$ & Max Temp $\left({ }^{\circ} \mathbf{C}\right)$ \\
\hline Cold & 12.37 & 19.08 \\
Cold-Cool Transition & 19.08 & 21.21 \\
Cool & 21.21 & 23.07 \\
Cool-Warm Transition & 23.07 & 24.95 \\
Warm & 24.95 & 29.93 \\
\hline
\end{tabular}

\subsection{SIZE}

Size classes were determined on the basis of upstream drainage area as opposed to stream order or width. Cumulative upstream drainage area $\left(\mathrm{km}^{2}\right)$ was provided as an attribute with NHD datasets. However, existing classifications for stream size (on the basis of upstream drainage area) were available from multiple sources, and each was based upon expert judgment in changes in stream behavior (Olivero and Anderson 2008). We used a combination of k-means clustering to explore potential breaks while also comparing to predefined solutions. We $\log (\mathrm{x}+1)$ transformed drainage area and then partitioned size into 
different clusters using a similar k-means clustering approach as described above (from two to 15 cluster solutions). SSD values minimized from five to seven cluster solutions. We then compared class breaks with those of the previous size classification and finalized our solution on seven size classes (Figures 7 and 8).

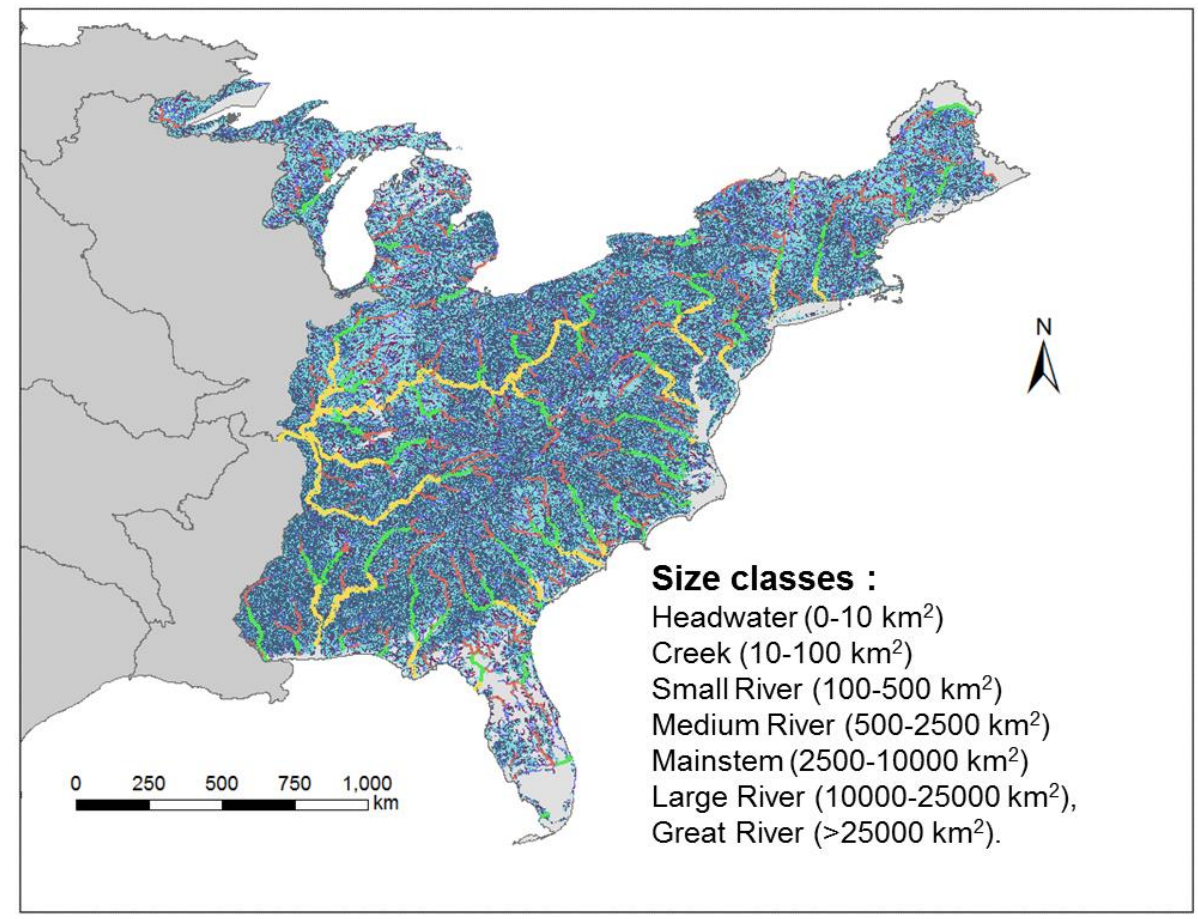

Figure 7. Size classification for the Eastern United States. 


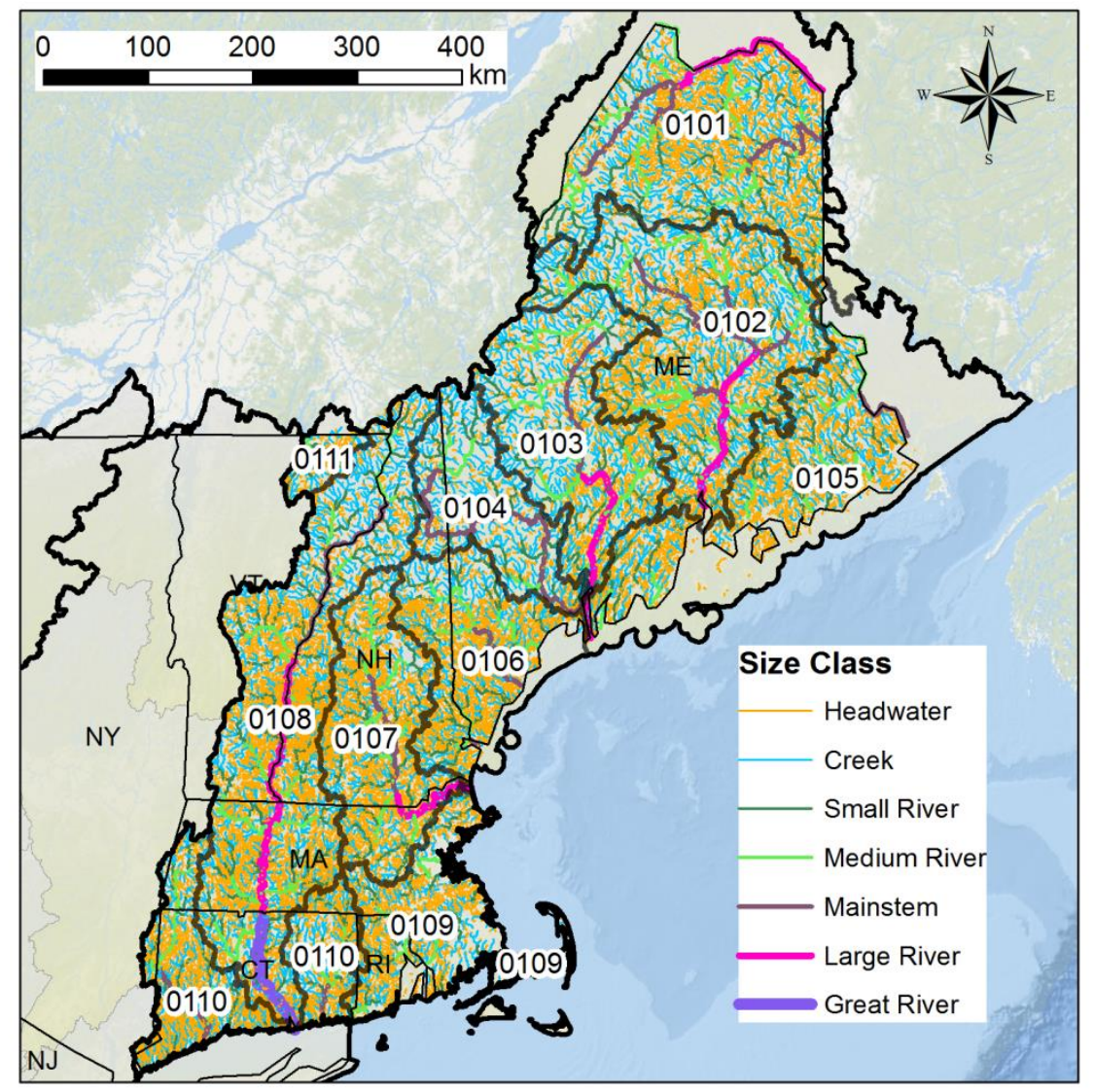

Figure 8. Example of size classification in stream reaches for the Northeast Region. Numbers represent sub-basins.

\subsection{GRADIENT}

Gradient (i.e., stream bed slope) is one of the several components used in the Rosgen stream classification (Rosgen 1994). Using the Rosgen template, we isolate nine breaks in gradient values that represented major divisions in stream types (Figures 9 and 10). Gradient values were provided as flowline attributes for NHD V1 stream segments. Values within our gradient classes also corresponded well to gradient breaks developed for similar stream classifications (Olivero et al. 2008). 


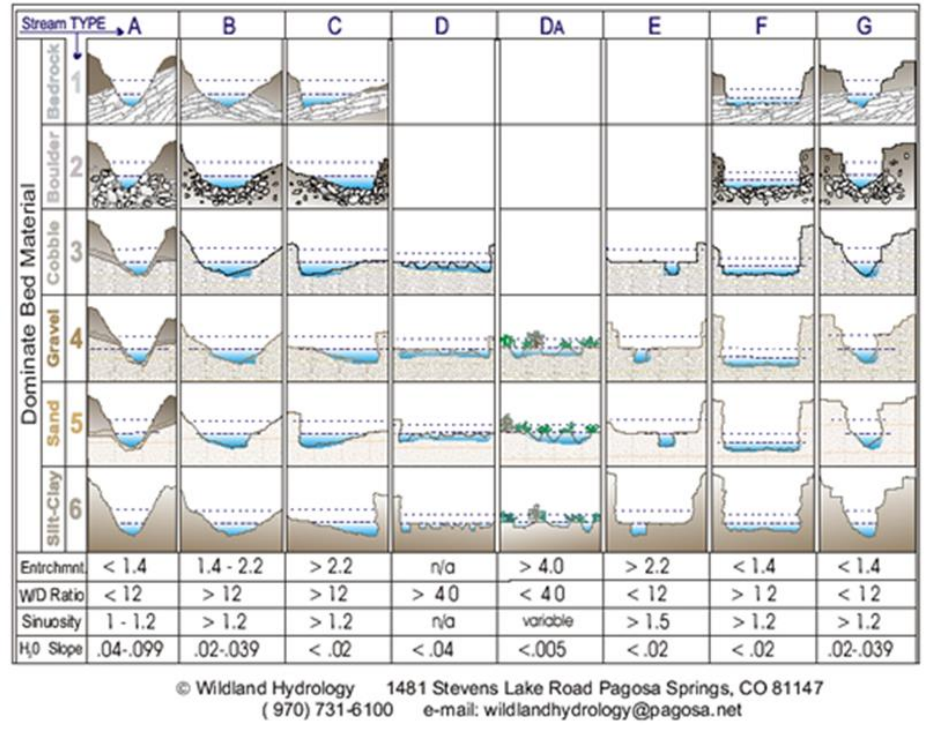

\section{Gradient classes :}

Very Low $<=0.001$

Low $=0.001-0.005$

Low Mod=0.005-0.02

Moderate $=0.02-0.04$

Moderate High=0.04-0.1

High $=0.1-0.2$

High-Steep $=0.2-0.4$

Steep $=0.4-1.0$

Very Steep $>1$

Figure 9. Major breaks in gradient proposed by Rosgen (1994) and gradient classes developed for the Stream Classification.

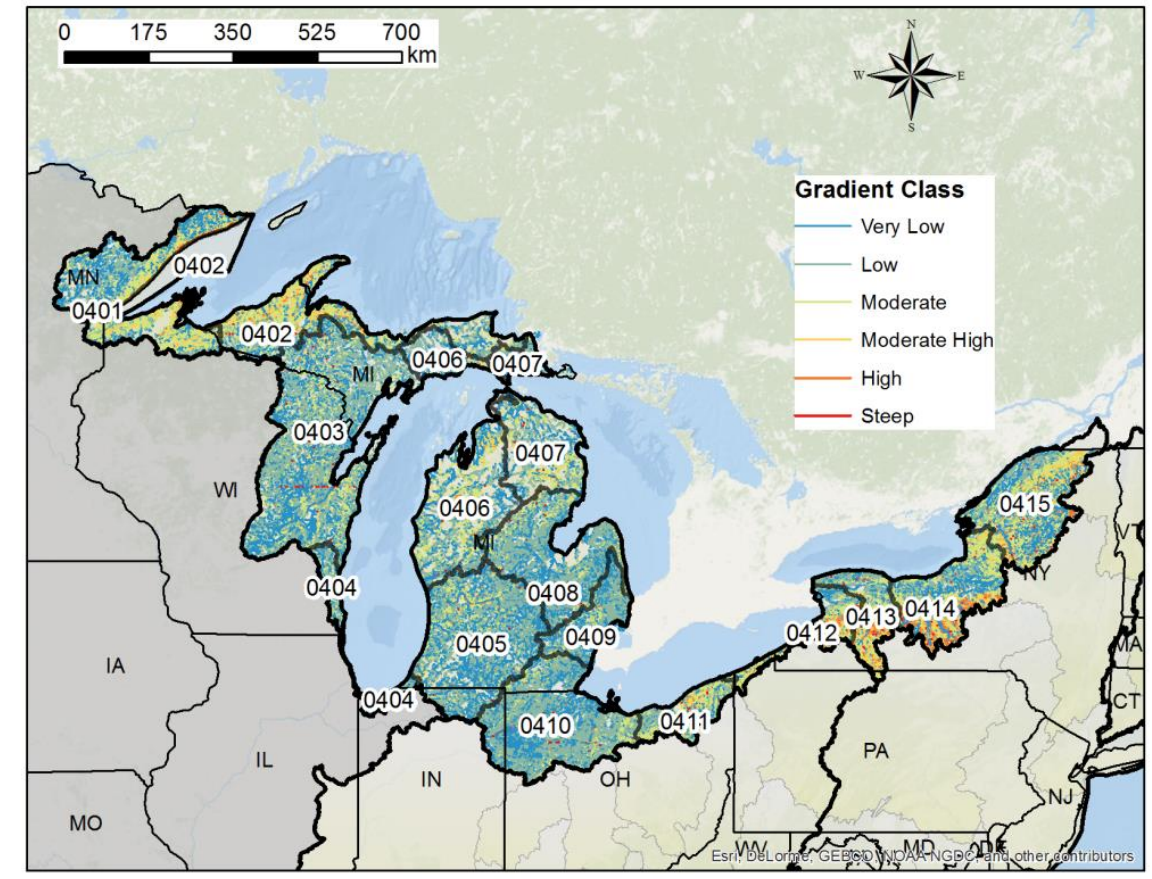

Figure 10. An example of gradient classes mapped to stream reaches in the Great Lakes Region. Numbers represent sub-basins.

\subsection{VALLEY CONFINEMENT}

Valley confinement refers to the potential of river channels to migrate and interact with their floodplain. A similar metric is entrenchment, technically defined as a ratio of floodplain width to bankfull width, where the floodplain is measured at two times the bankfull height. We used the Valley Confinement Algorithm (VCA) tool provided by Nagel et al. (2014) to delineate unconstrained valley bottoms (i.e., 
polygons) for all NHD Plus stream reaches (Figure 11A). Bankfull depth of the stream channel is estimated using an empirical function (Hall et al. 2007) based on regional precipitation data and drainage area for each stream reach. Flood height is dependent upon a user-defined flood factor, which is multiplied by bankfull depth to determine the flood height. Given the resolution of NHD plus stream reaches and the spatial resolution of digital elevation model (DEM) data, we determined that five times bankfull depth would be appropriate for defining valley bottoms. Based on DEMs, the program uses an algorithm to intersect flood height with the surrounding hillslope. Once valley bottoms are delineated, thresholds are required to determine whether stream reaches are unconstrained, constrained, or fall somewhere in between. For example, a valley bottom may not encompass an entire stream reach or may not extend laterally a sufficient distance beyond the bankfull width to be classified as 'unconstrained' (Figure 11B). We used field measurements to develop an empirical model to predict bankfull width for all stream reaches on the basis of drainage area, slope, elevation, precipitation, and region. Unconstrained stream reaches had a valley bottom that covered at least $50 \%$ of the stream reach length and had an area at least four times that of the bankfull width (Entrenchment ratios of $>=2$ are considered confined; thus, at the flood height of five times bankfull width, floodplain:bankfull width ratios of 4 should be conservative). Moderately confined stream reaches had valley bottoms that covered $25 \%$ to $50 \%$ of the stream reach length, or if greater than $50 \%$ coverage of stream length, valley bottoms had floodplain:bankfull width ratios between 2 and 4 . All other stream reaches were defined as confined (Figure 12).

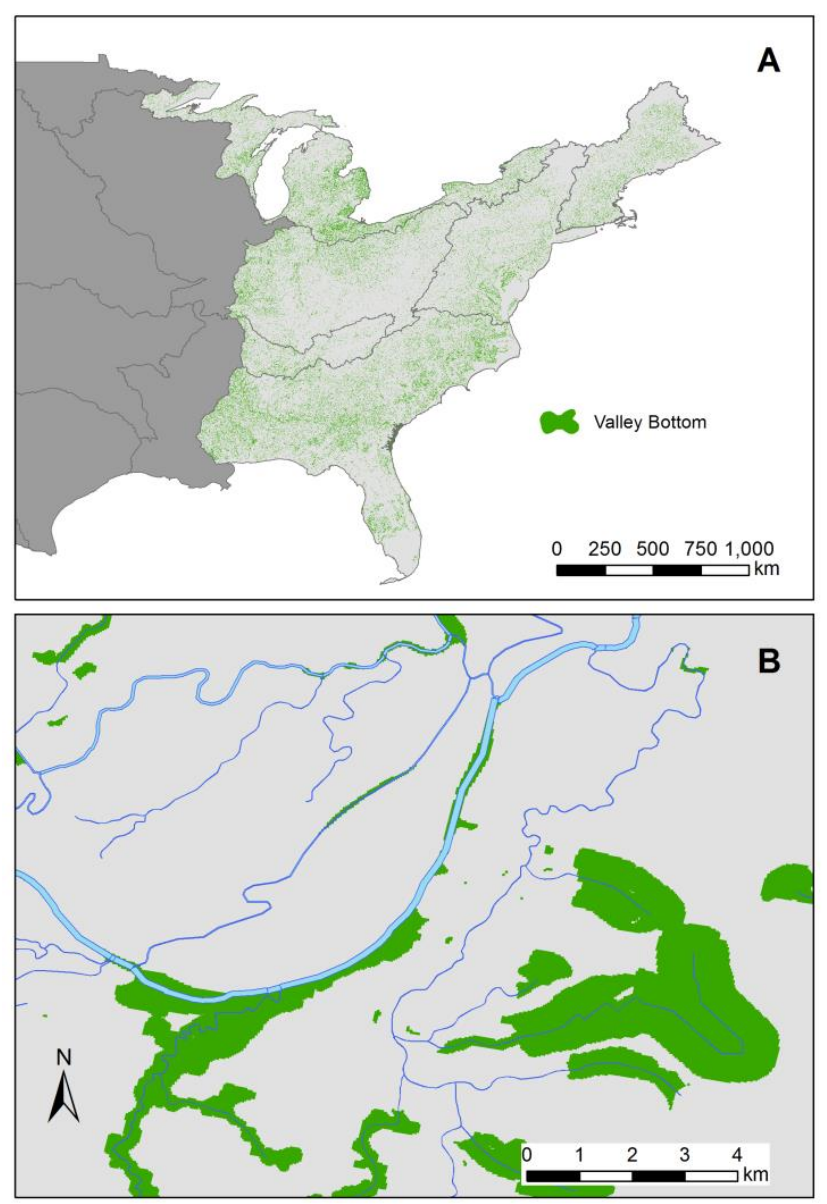

Figure 11. Valley bottoms delineated for the entire region (A). An example of bankfull width of stream reaches in relation to valley bottoms (B). 


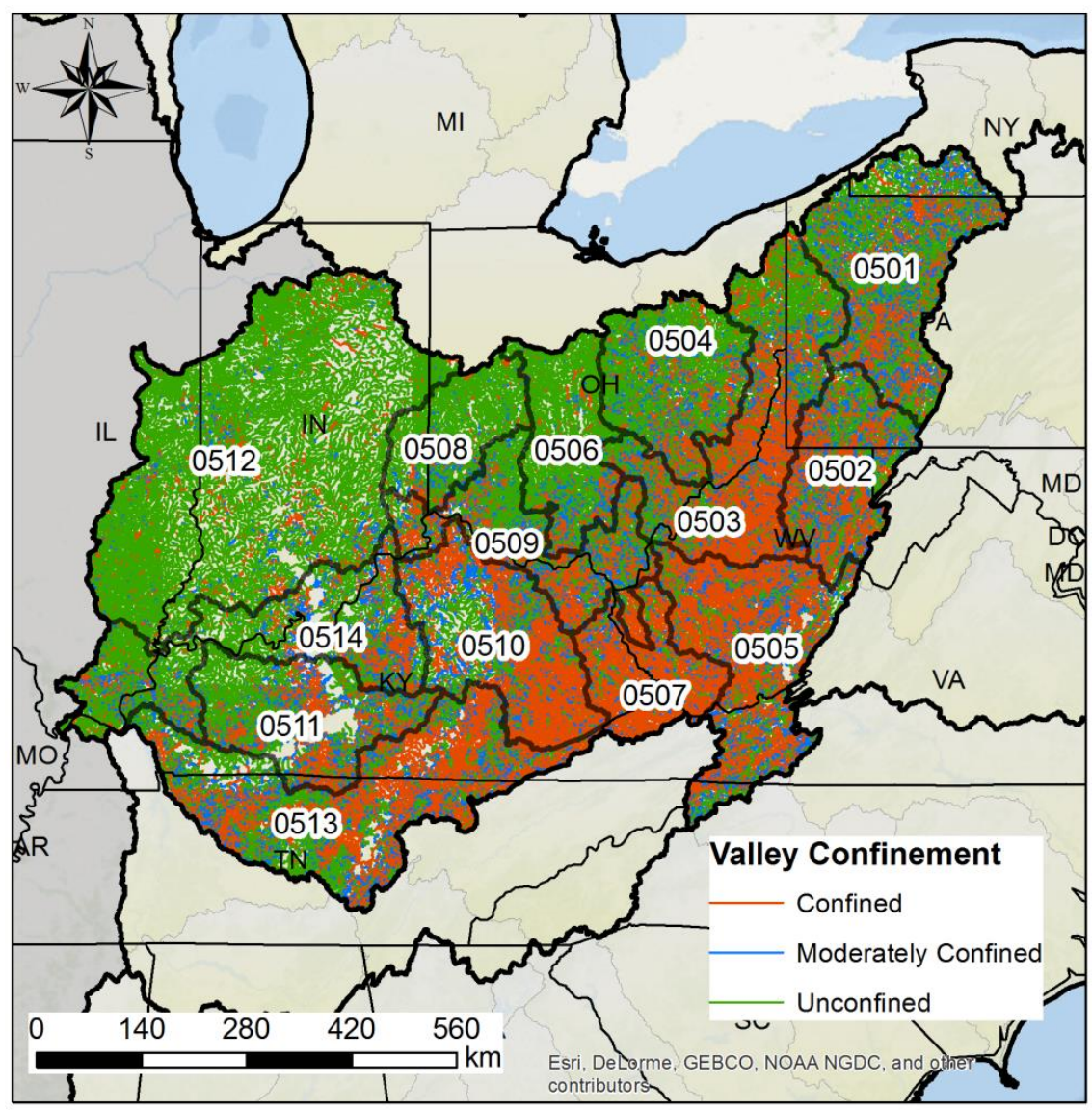

Figure 12. An exmaple of valley confinement classes for the Ohio Region.

\subsection{SUBSTRATE}

Similar to temperature, we compiled field measurements of surficial substrate assessments from multiple sources including stream habitat assessments from the U.S. Geological Survey National Water Quality Assessment Program, Environmental Protection Agency's (EPA) National Rivers and Streams Assessment, EPA's Regional Monitoring and Assessment Program, and EPA's Wadeable Streams Inventory. We selected sites that were representative of reference conditions. This resulted in approximately 460 sites where substrate conditions were assessed at reference sites (Figure 13A). At each site, multiple transects were placed and at multiple grids per transect, dominate substrate size (based on Wentworth scale) was visually estimated or manually measured. We then calculated percentage of grids falling into different substrate size categories, which included $\%$ fines $(0.03 \mathrm{~mm}), \%$ sand $(1 \mathrm{~mm})$, $\%$ gravel $(33 \mathrm{~mm}), \%$ big rock (1055 mm - cobble through boulder sizes), and \% bedrock $(2056 \mathrm{~mm})$. Based on percentages and average sizes with each substrate category, we estimated a weighted mean diameter of substrate at each site. Using a subset of the predictor ensemble for hydrology and temperature, we developed random forests to predict mean substrate diameter for 460 reference sites and then extrapolated those values to all NHD stream reaches (Figure 13B). 

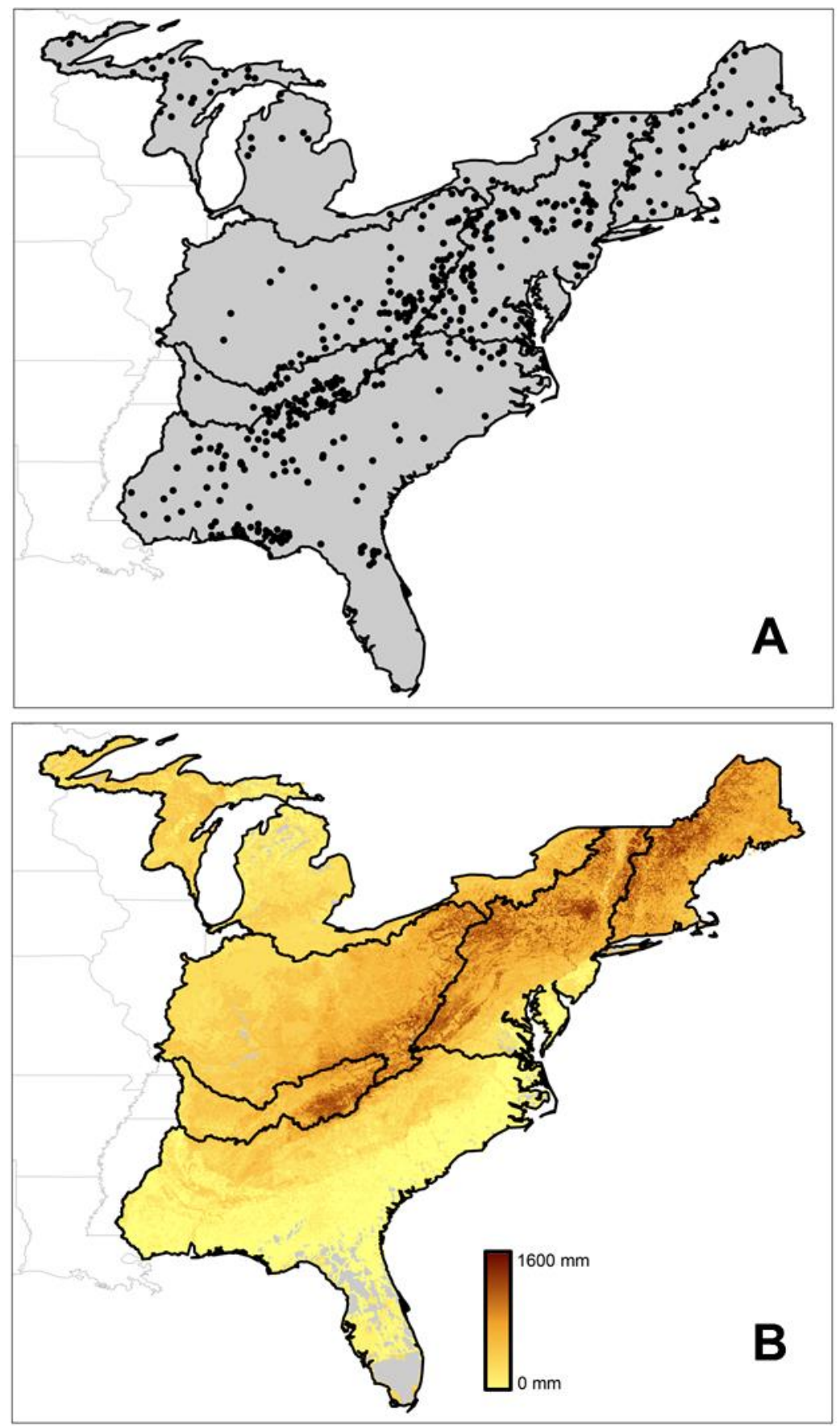

Figure 13. Reference sites $(n=460)$ were substrate conditions were assessed $(A)$, and predicted mean substrate diameter based on random forest models $(\mathrm{B})$.

We first used k-means to find distribution breaks in mean substrate diameters for the entire Eastern United States. We then compared this to the Wentworth substrate size classes to refine the breaks. The following substrate size classes resulted (Table 2). 
Table 2. Substrate classes and minimum and maximum diameters

\begin{tabular}{lcc}
\hline \multicolumn{1}{c}{ Substrate Size Class } & Min Diam $(\mathbf{m m})$ & Max Diam $(\mathbf{m m})$ \\
\hline Sand- Fine Gravel & 0 & 16 \\
Coarse Gravel & 16 & 64 \\
Small Cobble & 64 & 150 \\
Large Cobble & 150 & 300 \\
Small Boulder & 300 & 600 \\
Large Boulder-Bedrock & 600 & 1604 \\
\hline
\end{tabular}

\subsection{DISTURBANCE}

As described earlier, layered approaches provide the ability to consider both the natural and altered condition of streams. As a part of the National Fish Habitat Partnership (NFHP), scientists conducted a national assessment of landscape-related risks to fish habitats in streams (NFHP 2015). The scientific team summarized many metrics, including urban land cover and the number of dams, within each NHD catchment. In addition, metrics were also accumulated for the entire network upstream of each catchment; thus, local and cumulative upstream conditions play a role in defining the risk to fish habitats. Using fish sampling information as validation, a cumulative risk score was developed for NHD catchments (Figure 14).

In addition, we assessed the degree to which streams were regulated by dams using a Degree of Regulation (DOR) metric (Figure 15). DOR is calculated as the total cumulative storage volume by dams divided by the total annual flow volume multiplied by 100 . Typically streams with DOR $>4 \%$ show signs of altered hydrology; however, DOR commonly exceeds values of $100 \%$.

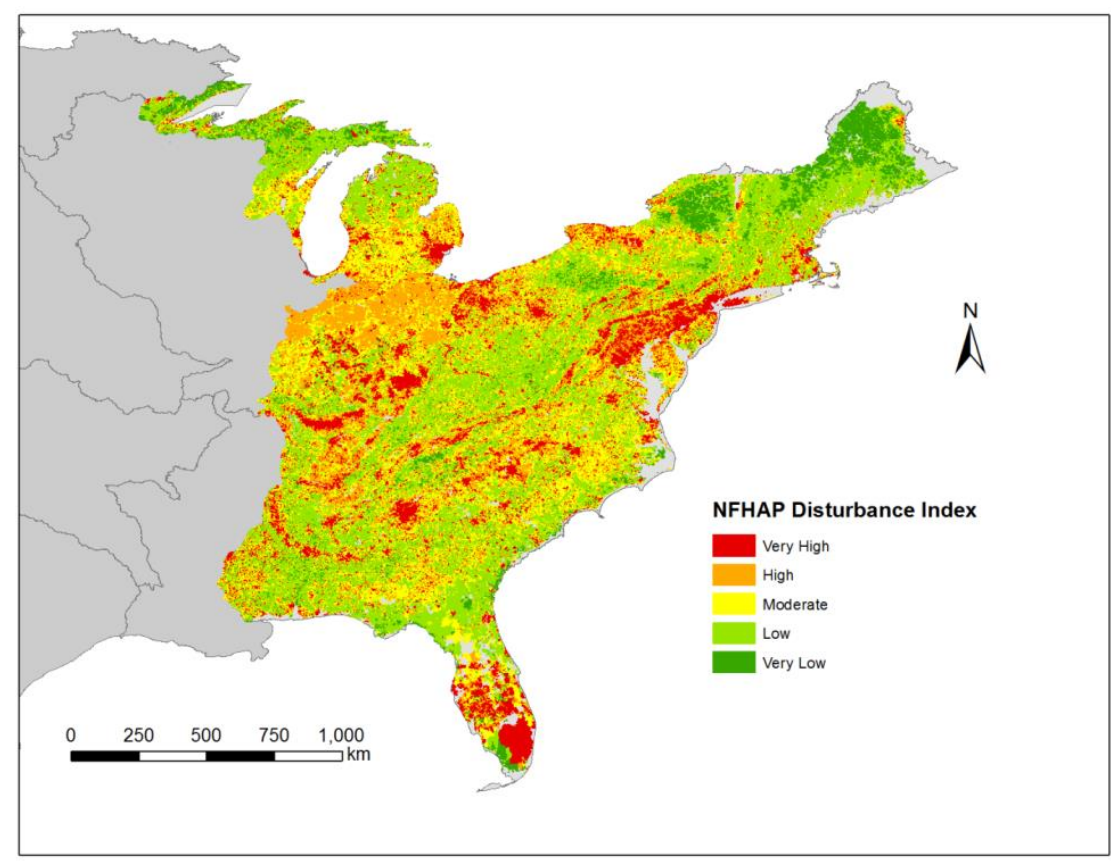

Figure 14. Landscape condition of stream reaches as measured by the National Fish Habitat Partnership Cumulative Disturbance Index. 


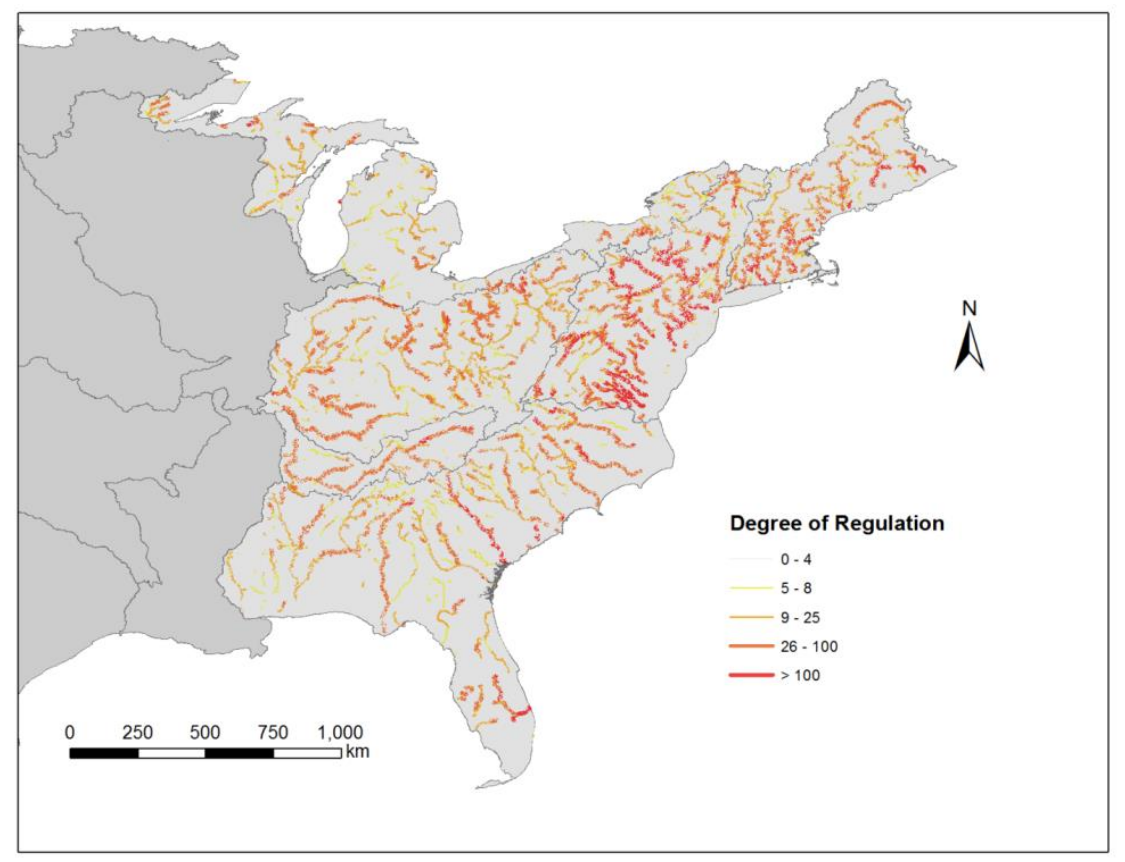

Figure 15. Degree of regulation by dams. Calculated as (cumulative upstream dam storage volume/total annual flow volume*100).

\subsection{HYDROLOGIC ALTERATION}

Although NFHP examines landscape condition, this does not necessarily imply that hydrology is altered in streams. Alternatively, streams draining landscapes classified as having 'low' impacts could, in fact, be hydrologically altered. Thus, it is important to explicitly model hydrologic alteration in stream segments using stream gages as observations. We modified a technique developed by Eng et al. (2012) to map hydrologic alteration in stream reaches (Figure 16). USGS stream gages representing reference hydrologic conditions in the conterminous United States ( 2400 gages) were identified by McManamay et al. (2014). We then identified over 5000 gages of non-reference conditions. Hydrologic statistics from non-reference gages were then compared to hydrology at non-reference gages to reference hydrologic conditions based on two methods, one using hydrologic class membership and another using predicted reference values for non-reference gages (Figures 16 and 17). 


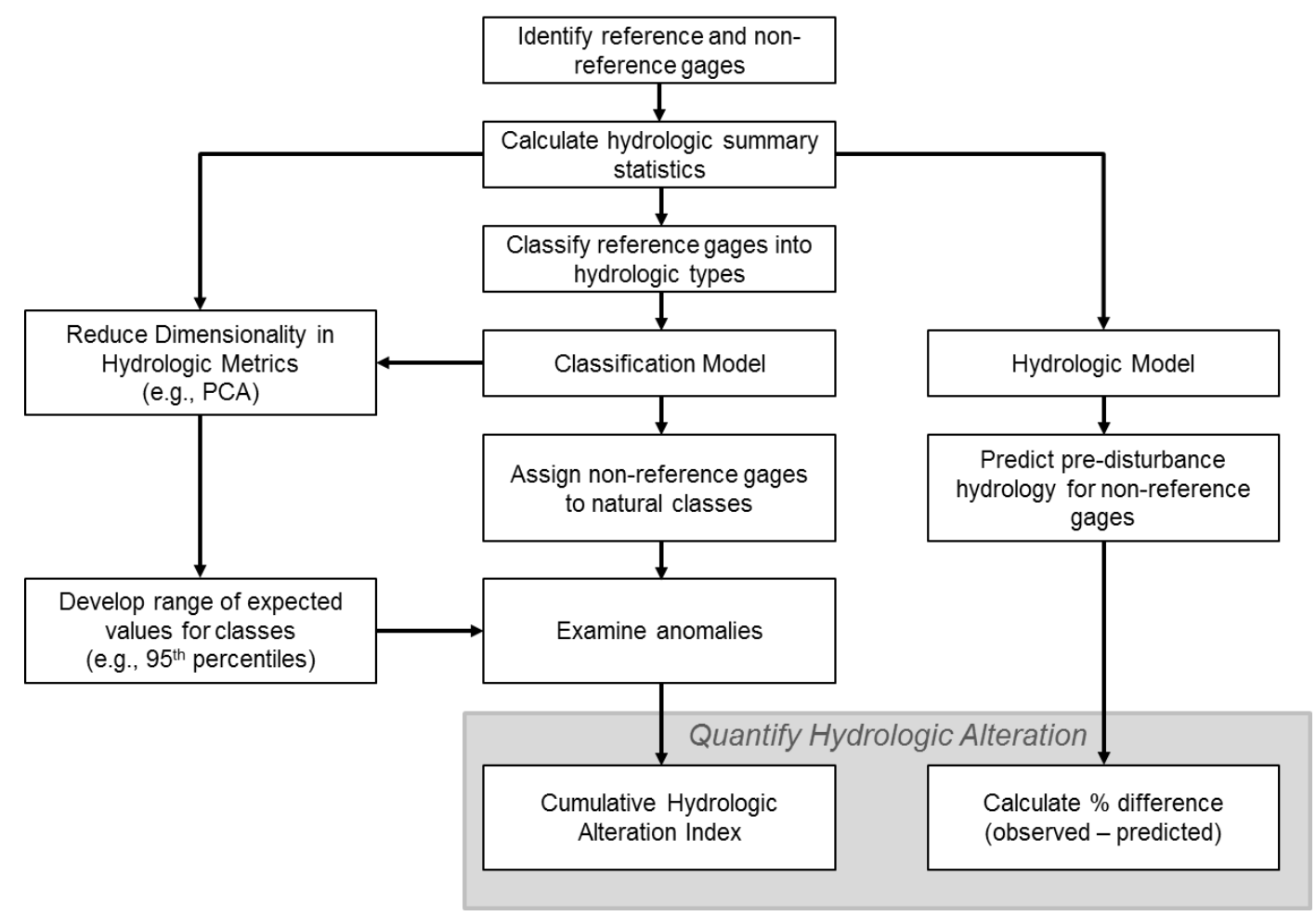

Figure 16. Method of calculating and mapping hydrologic alteration in stream reaches.
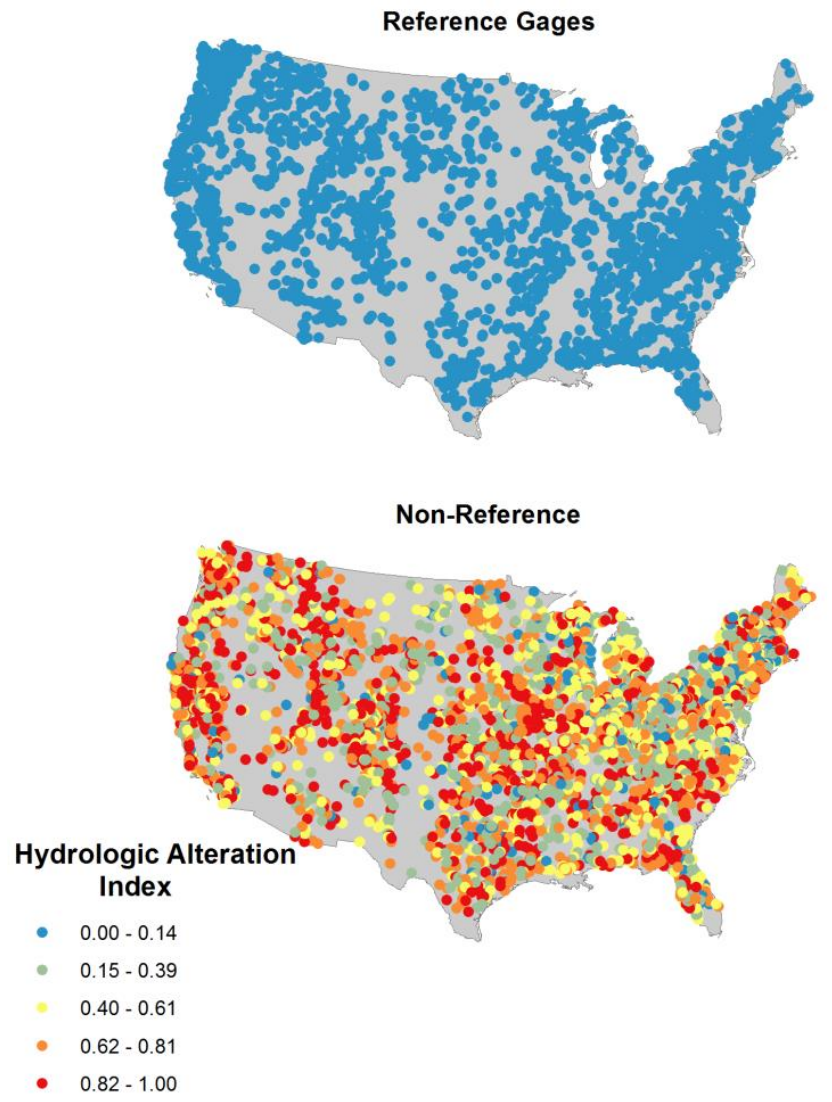

Figure 17. Reference and non-reference gages used in calculating the Hydrologic Alteration Index 


\subsection{ECOLOGICAL DATA AND VALIDATION}

As a part of the SCT, ecological data can be used to characterize communities within each class to determine appropriate mitigation. In addition, ecological data can be used to determine the relevance of stream classes (that is, how well classes explain variation in ecological data). We compiled fish community survey data and individual fish species records for the Eastern United States (Figure 18). These will aid in identifying species near facilities that warrant mitigation or identifying species that could colonize if conditions are improved. In addition, we will develop predictive models to determine how much variation each class explains in ecological data.

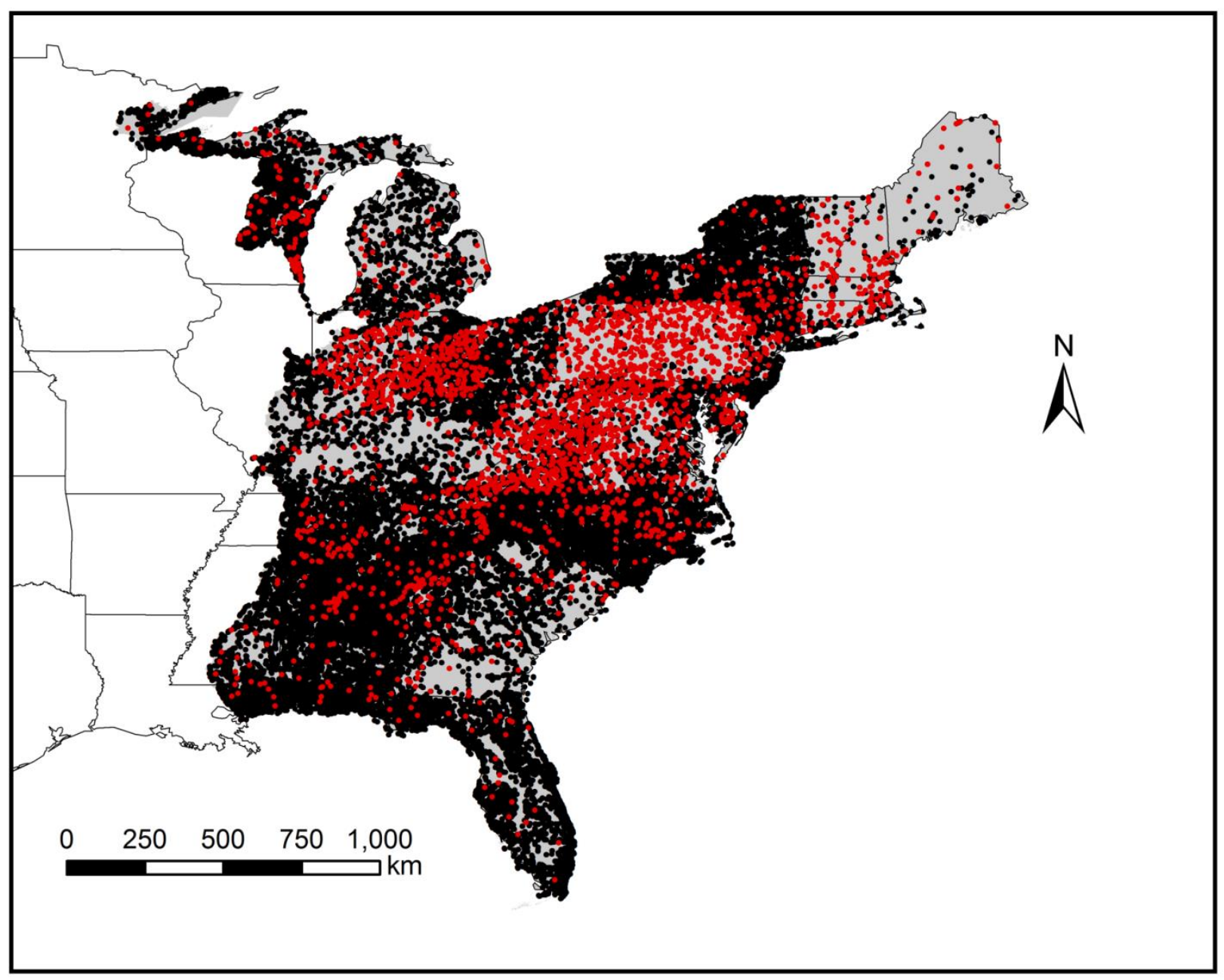

Figure 18. Fish community sites (red dots) and individual fish species records (black dots) in the Eastern United States. 


\section{APPLICATION OF SCT TO ENVIRONMENTAL MITIGATION FOR HYDROPOWER DAMS}

The Stream Classification Tool (SCT) is useful to environmental mitigation for hydropower dams in multiple ways (Figure 19). The purpose of the SCT is to create efficiency in the regulatory process by creating an objective and data-rich means to address meaningful mitigation actions. First, the SCT addresses data gaps as it quickly provides an inventory of hydrology, temperature, morphology, and ecological communities for the immediate project area, but also for surrounding streams. This includes identifying potential reference streams as those that are proximate to the hydropower facility and that fall within the same class. These streams can potentially be used to identify ideal environmental conditions or to identify desired ecological communities. Thus, the SCT provides some context for how streams may function and respond to dam regulation, and it provides an overview of specific mitigation needs. For example, streams are likely to respond differently to dam regulation based on their natural characteristics (McManamay et al. 2012, McManamay 2014). In addition to natural stream layers, we provide measures of hydrologic alteration, temperature alteration, and substrate alteration. Thus, the SCS can be used to predict what aspects of stream habitats may be relevant to restore or mitigate below dams.

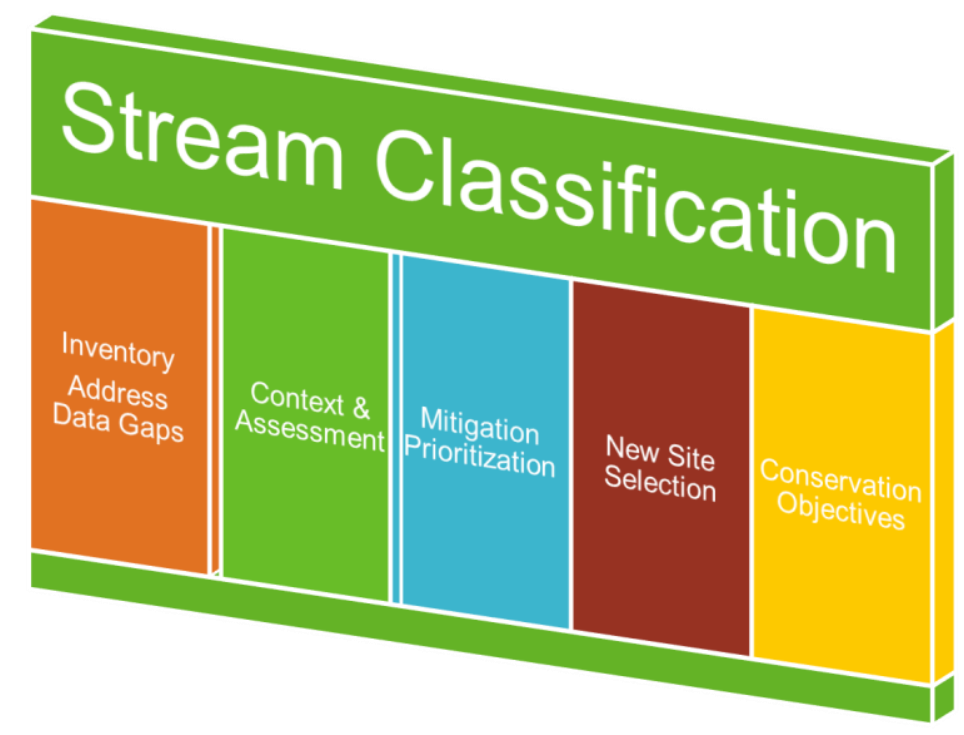

Figure 19. Conceptual model illustrating the utility of the Stream Classification Tool in environmental mitigation related to hydropower.

In addition to prioritizing mitigation, the SCT would be helpful in prioritizing sites for new hydropower development. For example, some hydrologic types may not be suitable for harnessing energy (e.g., intermittent, flashy types). In addition, some hydrologic, thermal, and morphological types may have a higher predisposition to disturbance following development. In other cases, the SCT may aid in prioritizing sites where dams could improve conditions. For example, the hydrologic alteration layer provides an indication of streams with highly modified flows, whereas the temperature layer (in addition to temperature monitoring stations) would provide an indication of temperature alteration. Dams can be structured to re-regulated flows (Pearsall et al. 2005) or to improve poor water quality conditions (Bednarek and Hart 2005). In a basin level analysis, we can identify reaches were regulation dams would have the greatest benefit (e.g., longest reach improved by hydrologic conditions). 


\section{GOOGLE EARTH TUTORIAL}

The purpose of the SCT is to provide stakeholders with easily accessible data that are standardized and objectively compiled for the purpose of making informed hydropower licensing decisions. As such, a key priority is disseminating these data via a medium that is broadly and freely available and easy to use. The following tutorial provides (1) an introduction to the use of Google Earth for accessing the STC, (2) a walk-through of data layers that are currently available for the eastern United States and (3) a projectspecific case study highlighting the ability of the SCT to identify environmental alterations associated with infrastructure and operation of a hydropower facility, as well as to identify potential environmental mitigation options.

\section{Downloading Google Earth Software:}

a. Google Earth is freely-available software that is used widely for viewing maps and aerial imagery. To begin the tutorial, download and install Google Earth (available from: https://www.google.com/earth/download/ge/agree.html).

\section{Exploring SCT data layers in Google Earth:}

a. We provide SCT data as map layers in .KMZ format, which can be easily distributed to stakeholders and viewed in Google Earth. Layers are available for download from the Stream Classification Tool Website (http://nhaap.ornl.gov/sct).

b. For this tutorial, we will use layers within the Upper Tennessee Sub-Region (HUC0601) (http://nhaap.ornl.gov/sct/huc06). Download all eleven layers available for Sub-Region 0601 to your desktop. Layers summarize hydrology, temperature, morphology, ecological components, and measures of hydrologic, temperature, and substrate alteration:
i. Class Hydrology.kmz
ii. Class Size.kmz
iii. Class Temperature.kmz
iv. Class Confinement.kmz
v. Class Gradient.kmz
vi. Class Substrate.kmz
vii. Class Disturbance.kmz
viii. Fish.kmz
ix. Sites Hydrology.kmz
x. Sites Temperature.kmz
xi. Sites Substrate.kmz

c. Next, open Google Earth software and add the Class Hydrology data layer:

File $\rightarrow$ Open $\rightarrow$ your file path $\rightarrow$ Class Hydrology.kmz. Click the black "Tour Guide" button on the bottom left to close the Tour Guide photo strip, making the entire map visible. 


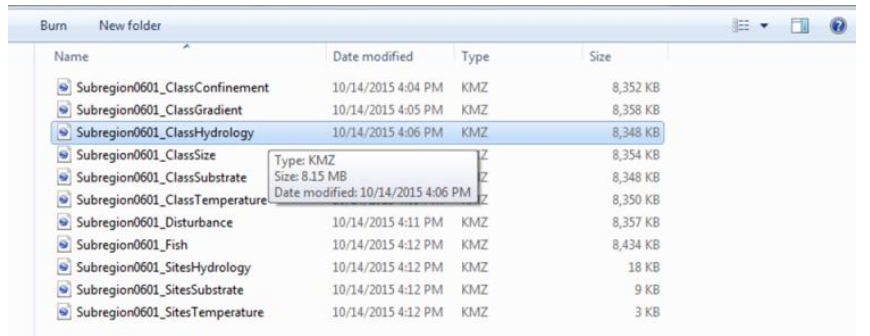

d. Double clicking the layer name in the "Places" panel on the left will automatically zoom the map to the extent of the data layer (in this case, the Upper Tennessee Sub-Region) (A). Use the standard Google Earth navigation tools located on the upper right side of the Google Earth interface to pan, zoom, and tilt the overhead viewing angle (B). Click on any flow line to open a dialogue box and view attributes of that flow line (C). When clicking on a flow line in the Class Hydrology layer, information for that specific flow line includes the stream/river name at the top, National Hydrography Dataset (NHD) identifier, cumulative upstream catchment area, the predicted Hydrologic Class (Hydrology), as well as the classes for the five other layers (temperature, substrate, confinement, size, and gradient).

e. Repeat steps $2 \mathrm{~b}$ through $2 \mathrm{~d}$, substituting the other 10 data layers, to explore other types of data available and their attributes (in the dialogue boxes) for the
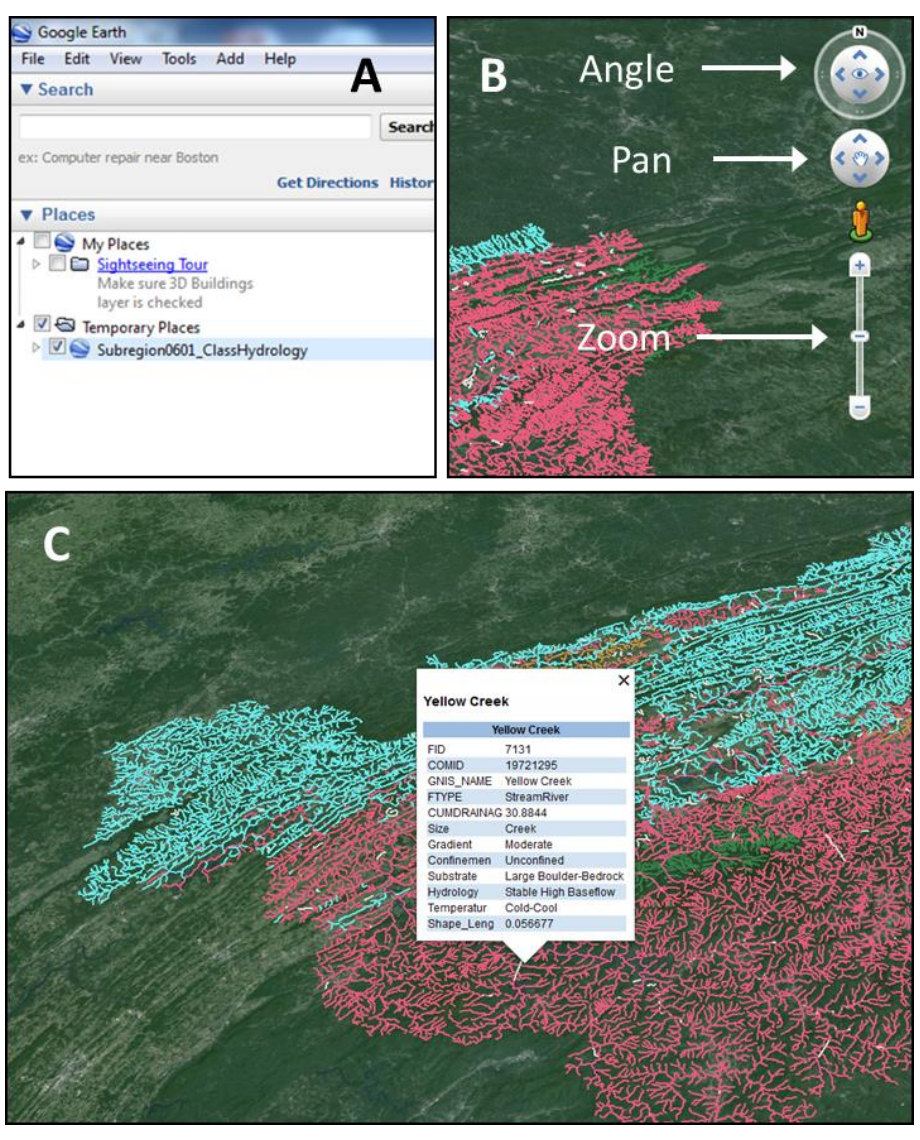
Upper Tennessee Sub-Region (Figure 15A-G).

f. Once multiple data layers have been opened in Google Earth, each layer can be turned on/off by checking/unchecking the adjacent box in the "Places" panel on the left side of the Google Earth interface. A layer can be removed from the current Google Earth session by right clicking on it and selecting "Delete". (**Note: in some cases, computer memory may be limited; thus, we recommend not loading all layers at one time, but having only 1-4 layers open at any time).

\section{A Case Study with Smoky Mountain Hydropower Project, North Carolina:}

\subsection{Assess Current Habitat Conditions, Disturbance, and Fish Community in the Cheoah River}

a. The Smoky Mountain Hydropower Project (formerly the Tapoco Hydropower Project) is a complex of four dams and two diversion structures located on the Cheoah and Little Tennessee Rivers in western North Carolina. Recent studies have investigated the environmental impacts of dam operation protocols before and after FERC relicensing, which included changes to the flow 
and sediment regimes to improve hydrologic, habitat, and thermal conditions in tailwater reaches, especially the 9.2 mile diversion-bypass of the Cheoah River below Santeetlah Dam (McManamay et al. 2010, 2013).

b. For this case study, type "Santeetlah Dam, Robbinsville, NC" in the search bar. Then click 'search'. Google Earth will automatically pan and zoom to the location of Santeetlah Dam and mark the location with a pin. Follow the Cheoah River from Santeetlah Dam to the junction of the Little Tennessee River. If zoomed in too close, use the navigation panel to zoom out to an appropriate scale.

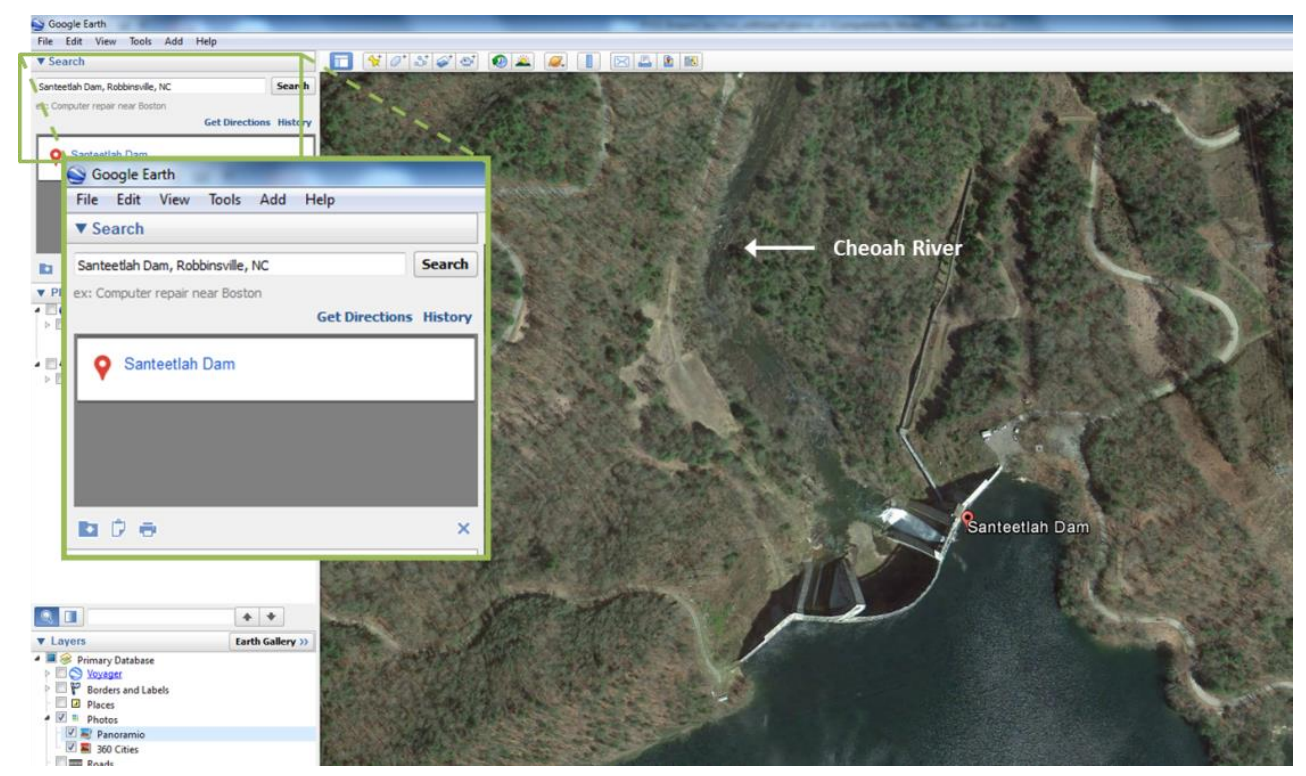

c. In the "Layer" panel on the left, click on "Photos" to view images along the Cheoah River. Look for icons along the river and click on each. This will help acclimate you to local conditions and habitat types.

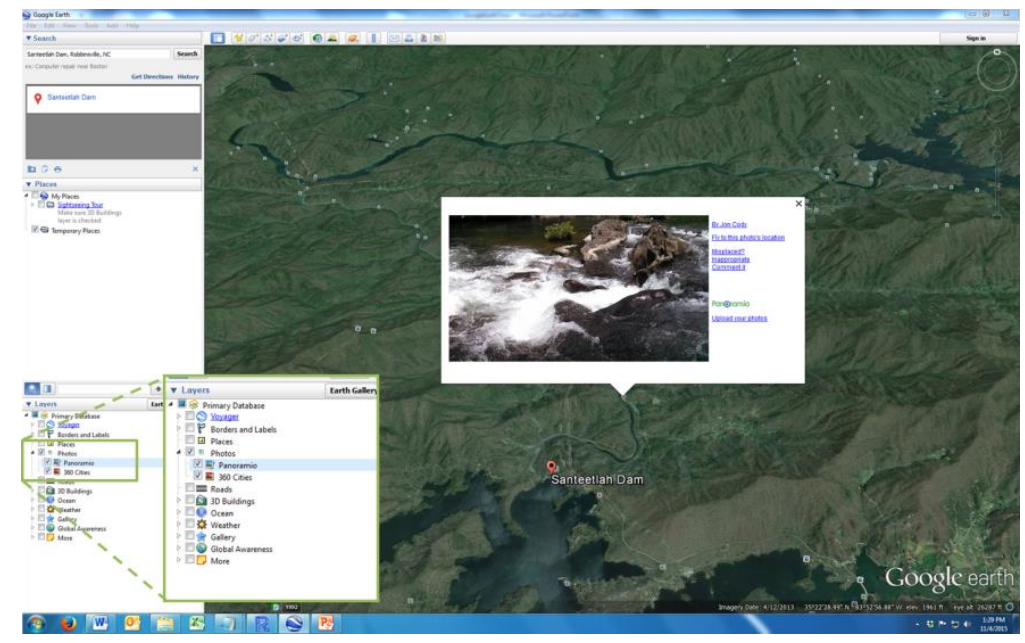

d. Next, load the Class Hydrology.kmz layer or check the box adjacent to that layer. 


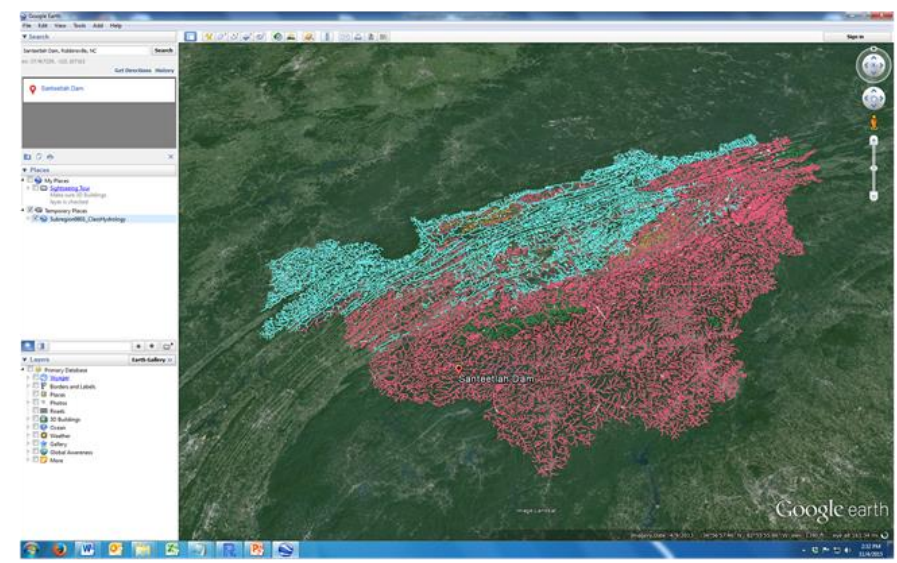

e. Zoom back to Santeetlah Dam. Visible at this extent are two key pieces of information:

i. A white line representing the diversion leaving Santeetlah Dam. The diversion bypasses the Cheoah River and carries water to a powerhouse on the Little Tennessee River system.

ii. The tailwater reach downstream of Santeetlah Dam is colored pink to designate the "stable high baseflow" hydrologic class. Clicking on flow lines in the

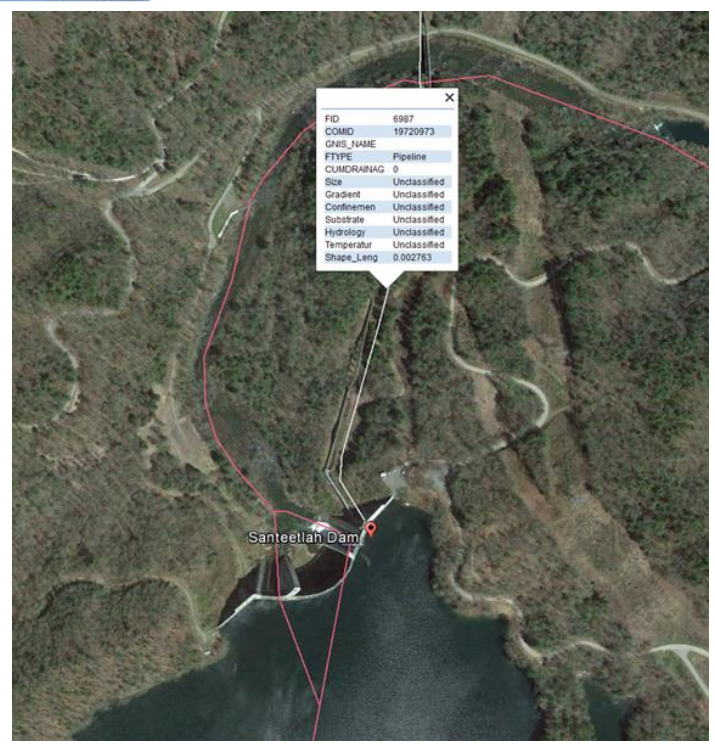
tailwater reach opens a dialogue box, showing the "Hydrology" as "Stable High Baseflow" and other relevant classes for other layers. 


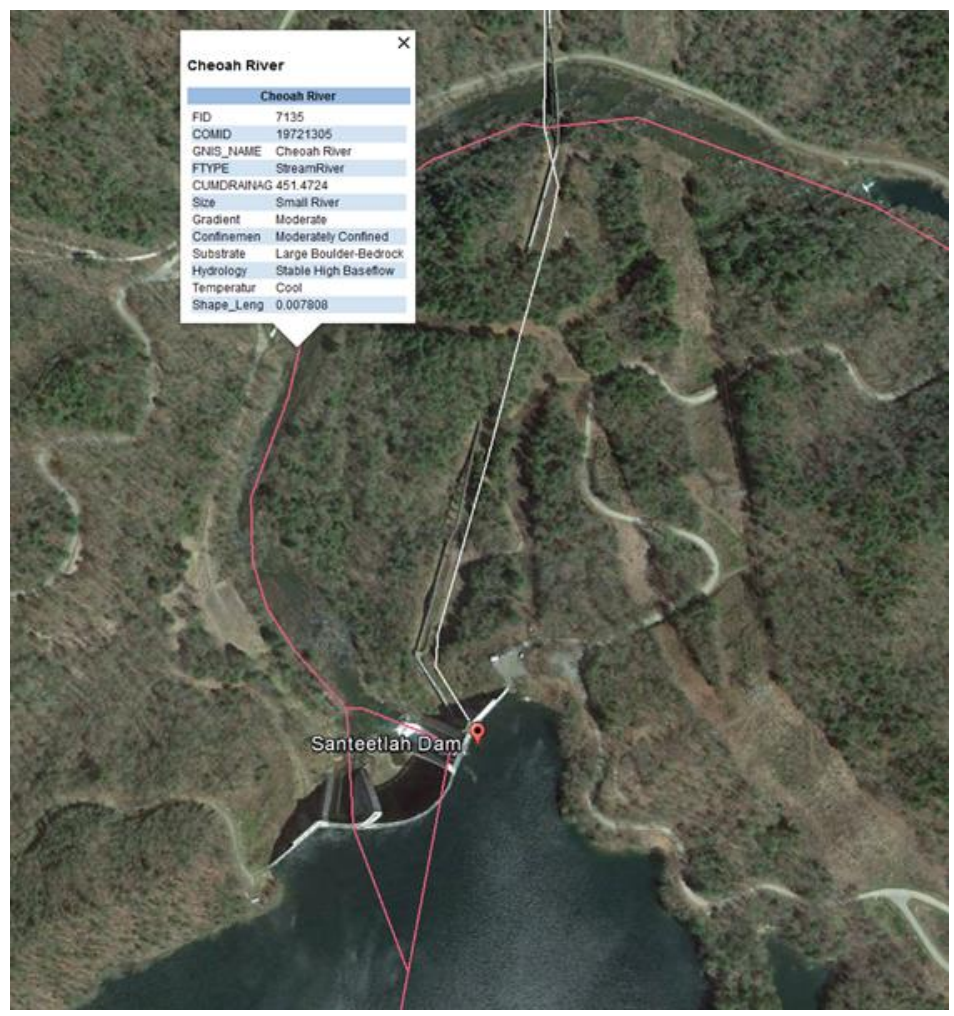

f. Next, load the Sites Hydrology.kmz layer.

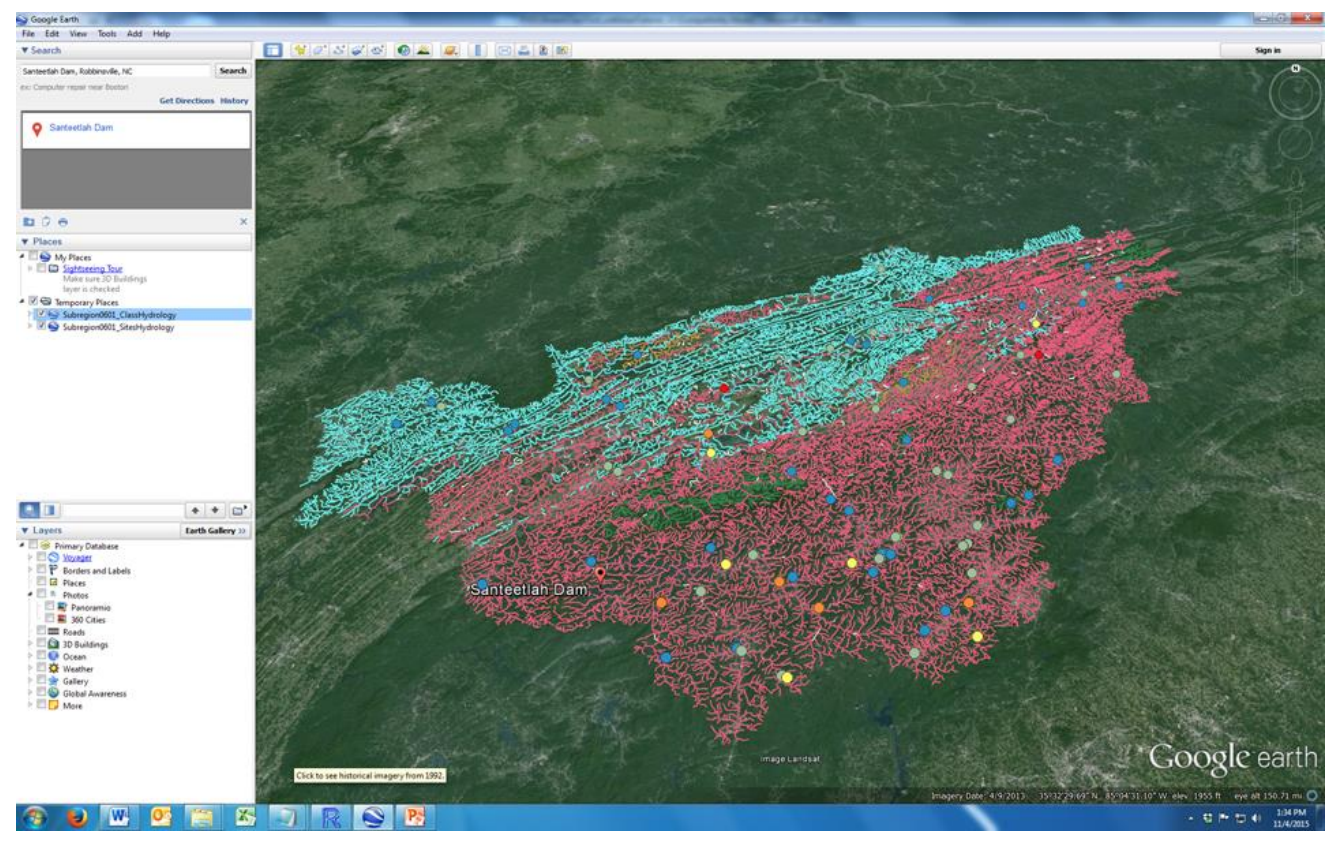

g. Zoom back to Santeetlah Dam. Turn off the Class Hydrology.kmz layer by unchecking the adjacent box in the "Places" panel (Figure 17A).

i. The layer is US Geological Survey stream gages with attributes that include measures of hydrologic alteration. Color coding represents DOR (Degree of Regulation) and ranges from low (blue) to high (red). Click on the site in the 
lower Cheoah River downstream of Santeetlah Dam to open the dialogue box. The information shows the name of the USGS stream gage and the Station ID. Also, it shows that the gage is regulated by dams, including information on DOR, upstream landcover (e.g., URBAN, AGR), and several measures of hydrologic alteration. In particular, note that alteration in mean daily flow (nMA1) is -0.652 , indicating a $65 \%$ loss in mean daily flows (from diversion at Santeetlah Dam). In comparison, alteration in daily $\mathrm{CV}$ (nMA3) is 0.877 , indicating an $88 \%$ increase in daily flow variation.

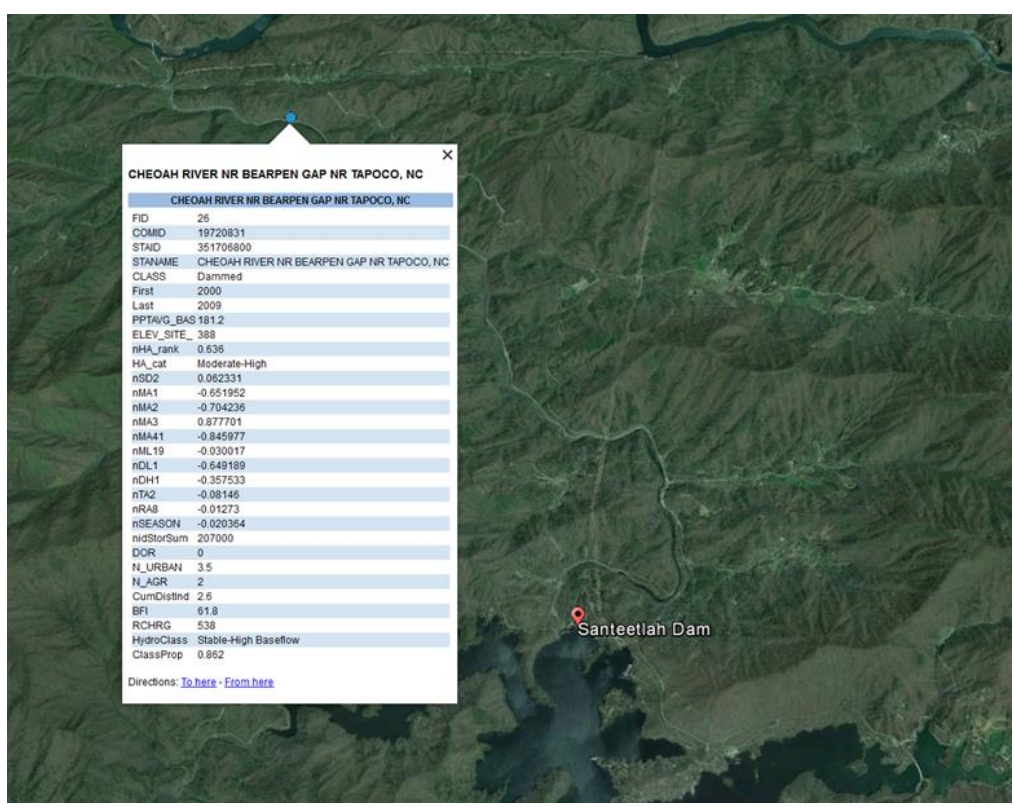

h. Next, load the Class Temperature.kmz and the Sites Temperature.kmz layers.

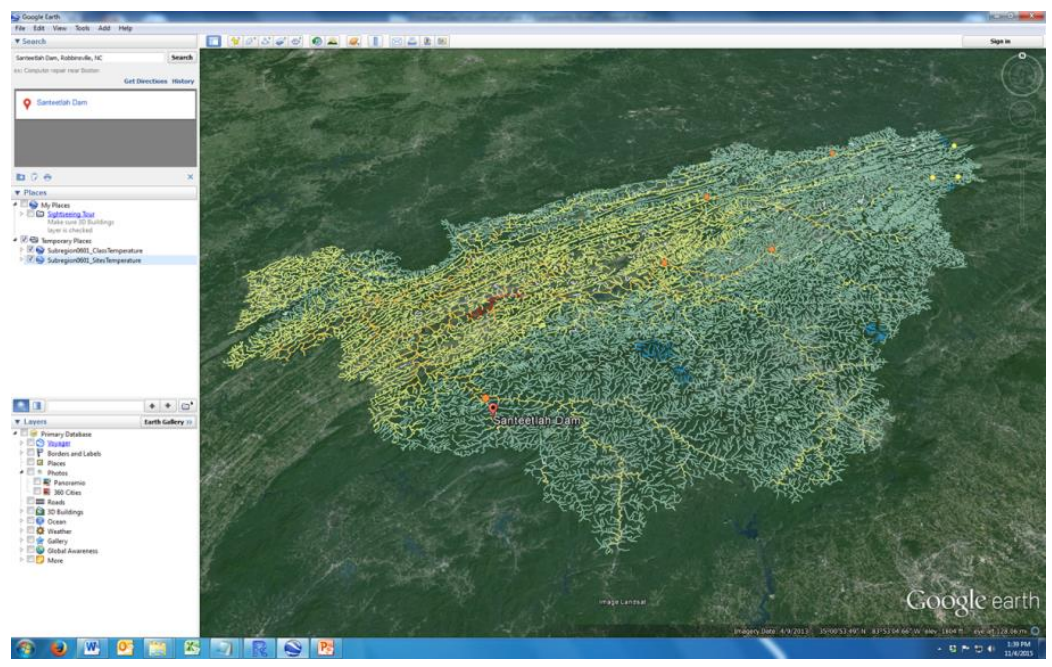


i. Zoom back to the Santeetlah Dam extent. Turn off the other layers by unchecking the adjacent boxes in the "Places" panel (Figure 17B).

i. The Class Temperature layers shows that natural summer temperatures are higher (orange) along the Little Tennessee River mainstem and lowest (yellow, green, and blue) in the smaller tributaries. Natural summer temperatures are classified as "Cool" for the Cheoah River $\left(21-23^{\circ} \mathrm{C}\right)$.

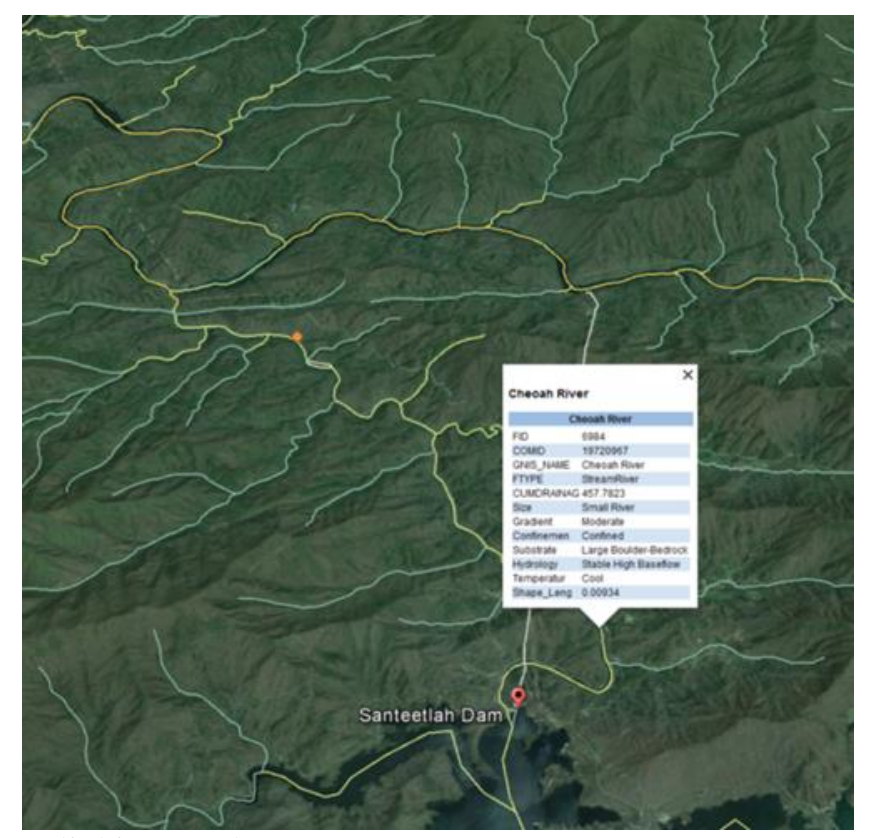

ii. Clicking on the temperature monitoring site downstream of the Santeetlah Dam diversion opens the dialogue box, which shows the observed temperature (Obs_Temp), the predicted natural temperature (Pred_Temp), and the difference between natural and observed (Temp_Devia). Temperature deviation is $+2.7^{\circ} \mathrm{C}$, which suggests that Santeetlah Dam has a warming effect on water temperature by diverting flows.

j. Load the Class Substrate.kmz layer and the Sites Substrate.kmz layer.

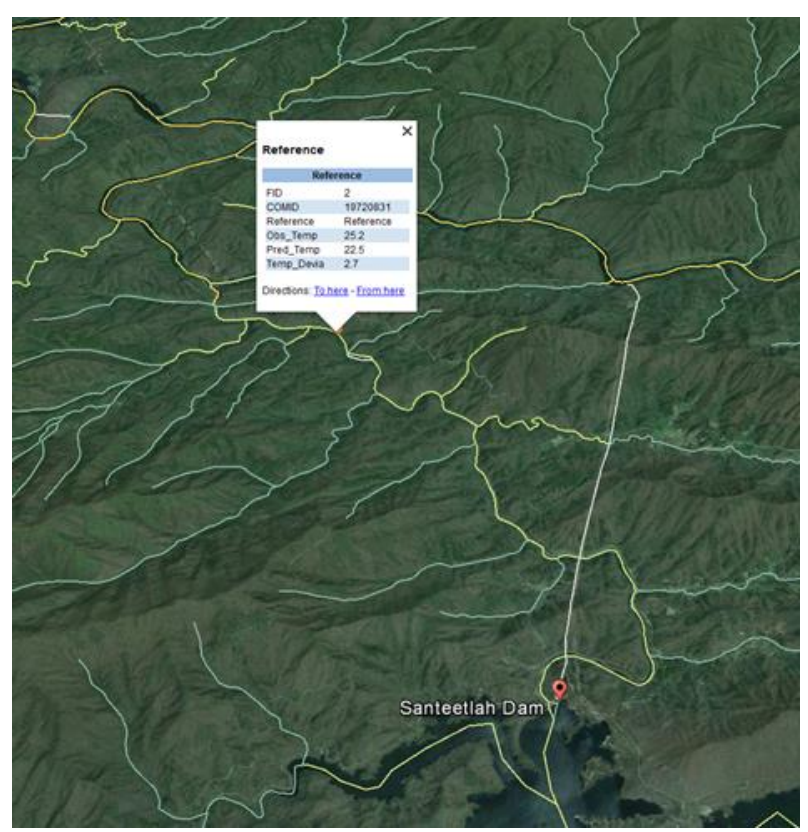




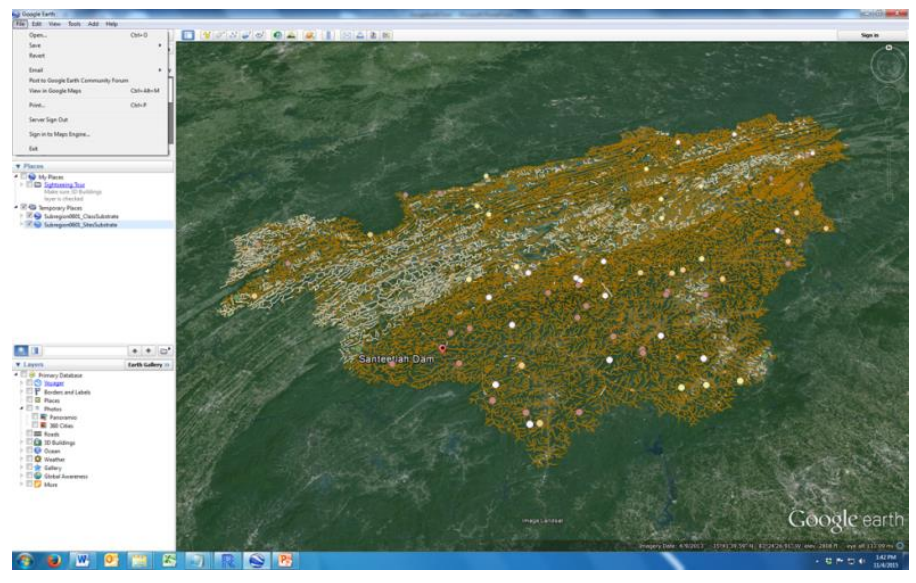

k. Zoom back to the Santeetlah Dam extent. Turn off the other layers by unchecking the adjacent boxes in the "Places" panel.

i. Most of the region, including the Cheoah River is classified as "Large BoulderBedrock" substrate class. Clicking on the photos along the Cheoah River that show images of the stream channel corroborates these estimates.
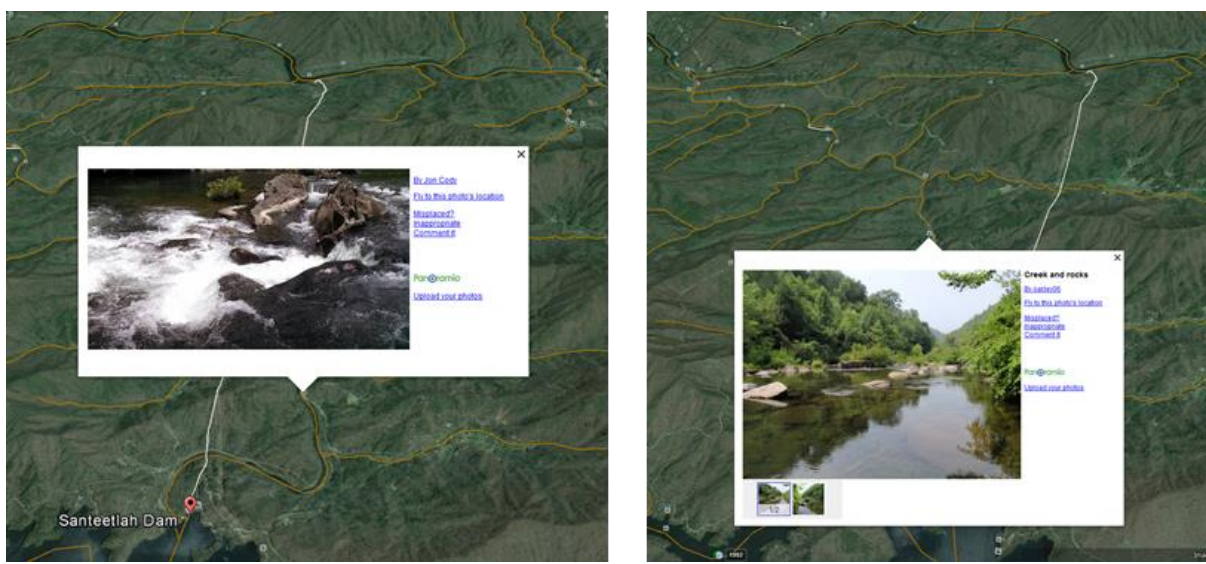

ii. Click on the substrate monitoring sites in the area surrounding the Cheoah River and Santeetlah Dam. Notice the amount of \%fine, \%sand, and \%gravel in surrounding unregulated streams. Most managers have noted that finer particles are typically non-existent in the Cheoah River below Santeetlah Dam because of lack of bedload transport and armoring of the streambed surface.

1. Lastly, load the Fish.kmz file. Turn off any other layers by unchecking the adjacent box in the "Places" panel.

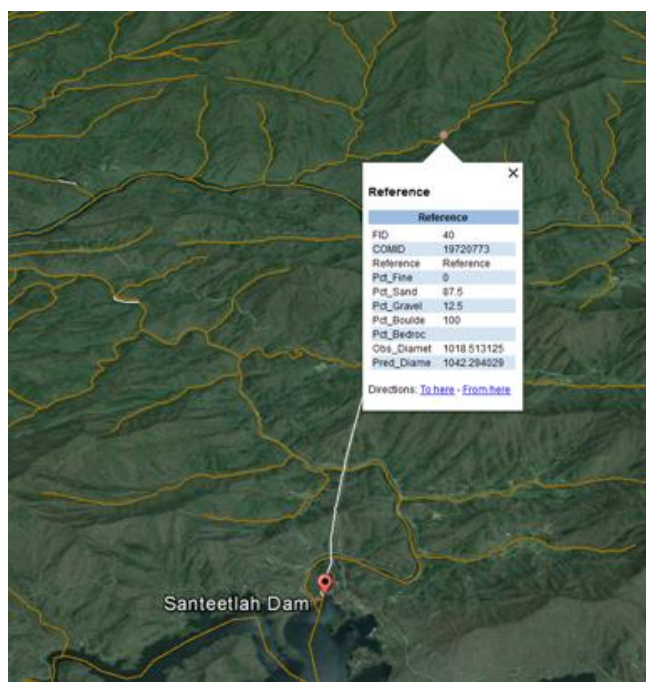


i. Flowlines from which fish species were collected and identified are colored according to the type of survey, with green representing flowlines consisting of presence only surveys, blue represented presenceabsence or community type surveys, and white represented unsampled reaches.

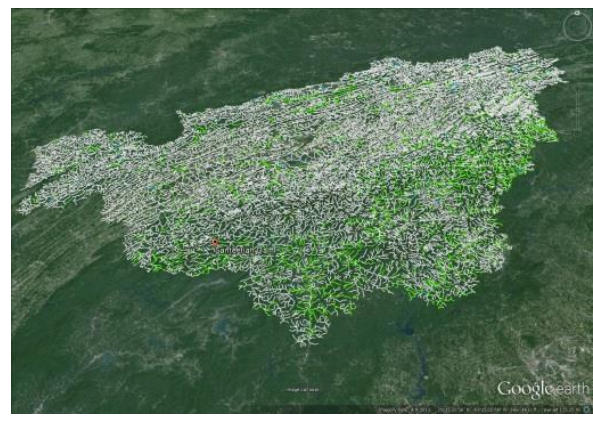

ii. Zoom back to Santeetlah Dam. Clicking on a sampled flowline opens a dialogue box showing with a list of species that were present during the sampling event. For the mainstem Cheoah River and all incoming tributaries downstream of Santeetlah Dam to the junction with the Little Tennessee River, click on each stream segment and talley the total number of fish species detected.

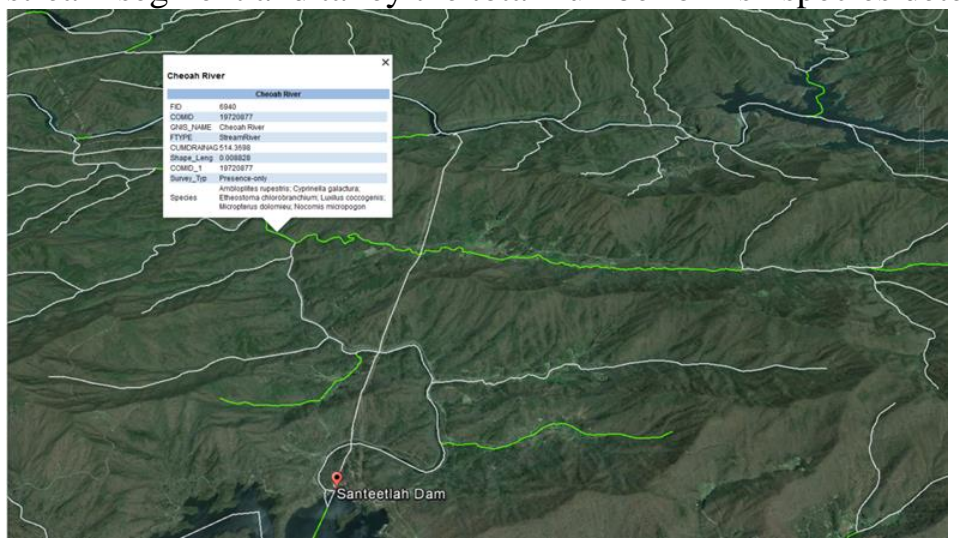

iii. Within the mainstem Cheoah River and incoming tributaries (between Santeetlah Dam and the Little Tennessee River), 14 fish species were recorded:

\begin{tabular}{|llc|}
\multicolumn{1}{c}{ Species } & Tribs & Mainstem \\
\hline Ambloplites rupestris & & $\mathrm{X}$ \\
\hline Cyprinella galactura & & $\mathrm{X}$ \\
\hline Etheostoma chlorobranchium & $\mathrm{X}$ \\
\hline Hypentelium nigricans & $\mathrm{X}$ & \\
\hline Lepomis macrochirus & $\mathrm{X}$ & \\
\hline Luxilus coccogenis & & $\mathrm{X}$ \\
\hline Micropterus dolomieu & & $\mathrm{X}$ \\
\hline Nocomis micropogon & & $\mathrm{X}$ \\
\hline Oncorhynchus mykiss & $\mathrm{X}$ & \\
\hline Percina aurantiaca & & $\mathrm{X}$ \\
\hline Rhinichthys atratulus or obtusus & $\mathrm{X}$ & \\
\hline Rhinichthys cataractae & $\mathrm{X}$ \\
\hline Salmo trutta & $\mathrm{X}$ \\
\hline Semotilus atromaculatus & $\mathrm{X}$ \\
\hline
\end{tabular}




\subsection{Find a Reference Stream and Case Study Stream for the Cheoah River}

a. Load any one of the six natural stream class layers (Class Hydrology.kmz, Class Temperature.kmz, Class Gradient.kmz, Class Size.kmz, Class Confinement.kmz, Class Substrate.kmz)

i. Click on the segments of the Cheoah River below Santeetlah Dam and make notes of the types of six classes.

ii. Above the entrance of Yellow Creek (the largest tributary), most segments of the Cheoah River are classified as the following: Small River, Moderate Gradient, Confined, Large Boulder-Bedrock, Stable-High Baseflow, and Cool (SR-MG-CLBBK-SHBF-C). Below Yellow Creek, most segments are identical to those above the tributary, with the exception that the river is classified as a Medium River.
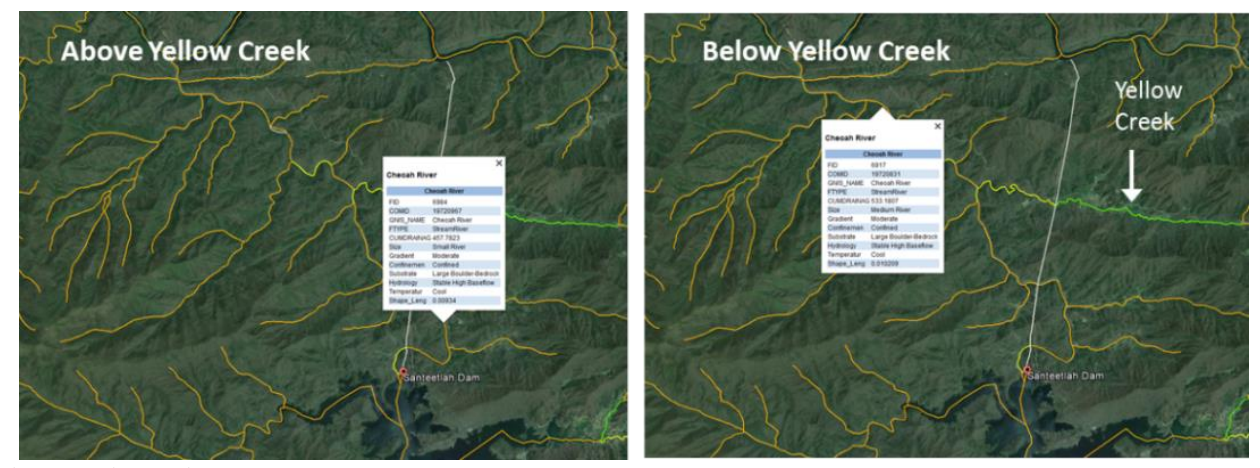

b. Load the Disturbance.kmz layer.

c. Zoom back to Santeetlah Dam and the Cheoah River.

i. Notice that all tributaries above Santeetlah Dam and those incoming to the Cheoah River are blue (indicating low disturbance and little dam regulation). In contrast, the mainstem Cheoah is orange indicating high dam regulation.

ii. Clicking on the first stream segment below Santeetlah Dam opens the dialogue box and shows that upstream Dam Storage is 207,000 acre feet. Degree of regulation (dam storage/annual flow volume*100) is $60.7 \%$, indicating high regulation. Upstream Urban and Agricultural land cover is low, only 3.5\% and $2 \%$, respectively.

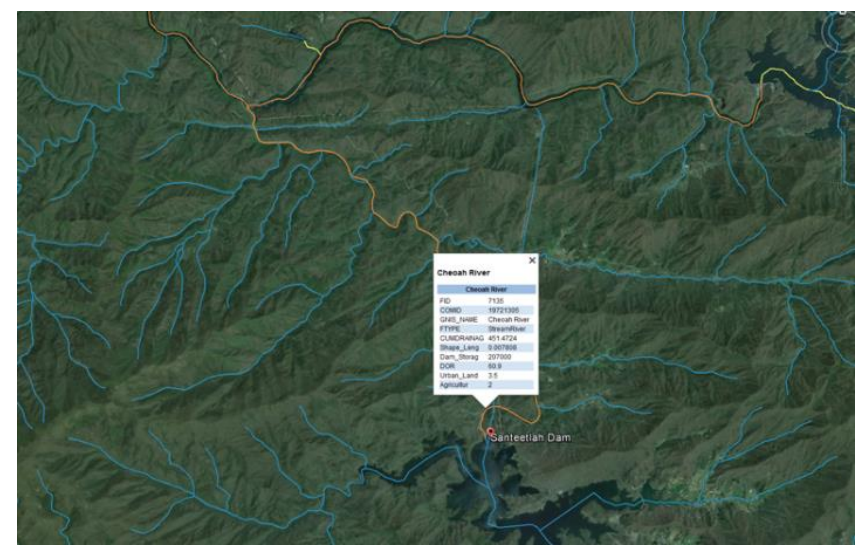


d. In the search panel, type "Bald River Falls, TN" and click "Search". Unclick the box adjacent to Distubance.kmz layer and check the box adjacent to a natural class layer in the "Places" panel.

i. Google Earth will zoom to the Bald River Falls, which occurs directly at the junction of the Tellico River and Bald River (a smaller tributary). The interest here is the Tellico River. Click on photos and examine images of the mainstem Tellico River.

ii. Click any one of the nearby stream segments in the Tellico River. Notice that the Tellico River has the same stream class as that of the Cheoah: Small River, Moderate Gradient, Confined, Large Boulder-Bedrock, Stable-High Baseflow, and Cool (SR-MG-C-LBBK-SHBF-C).

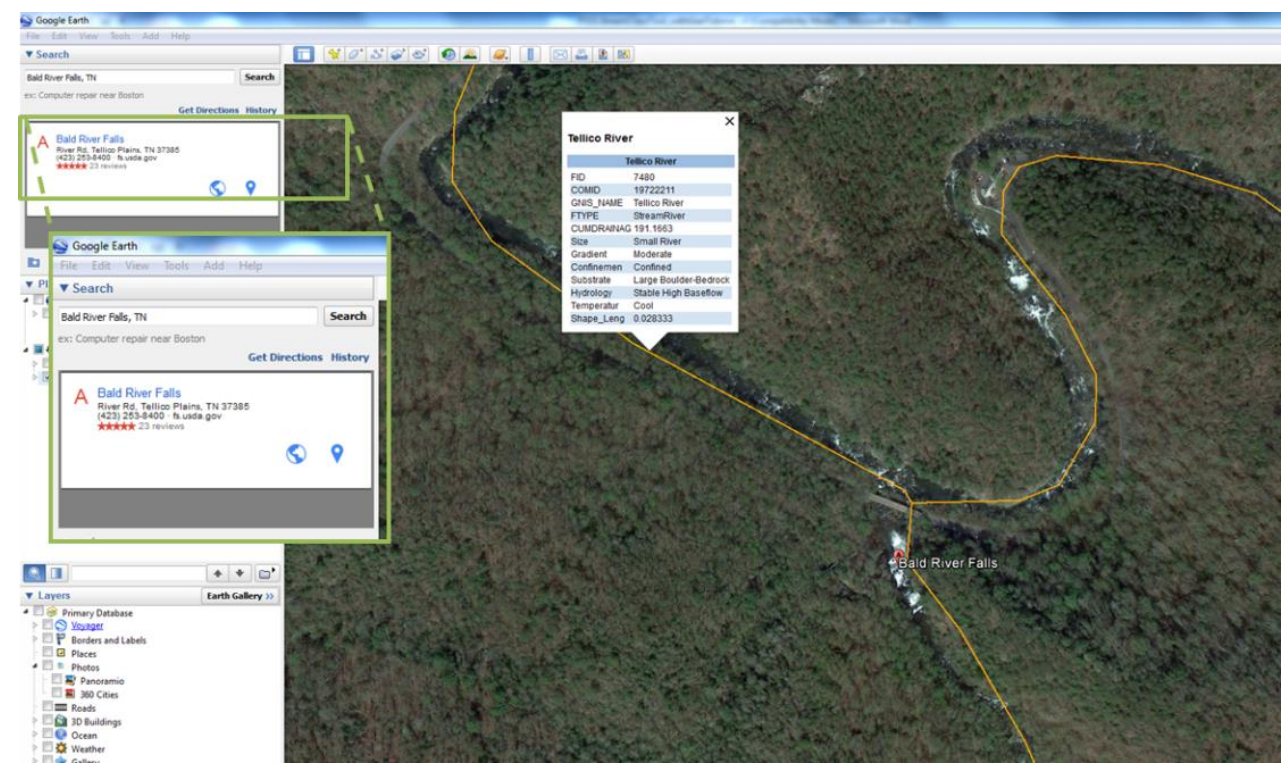

iii. Unlick the box adjacent to the natural class layer and click to open the Disturbance.kmz layer.

1. Notice that the Tellico River is colored blue and has very little upstream disturbance. Thus, the Tellico River may be a good choice of a reference stream to guide management in the Cheoah River.

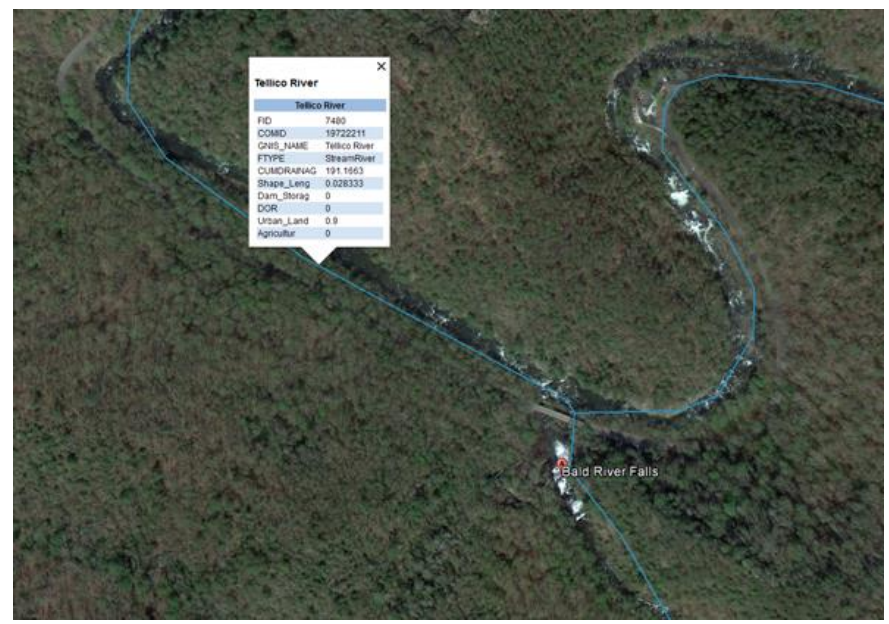


iv. Next unclick the box adjacent to the Disturbance.kmz layer and open the Fish.kmz layer.

1. Scan the area and examine the species detected in the Tellico River and compare to the species list in the Cheoah River.

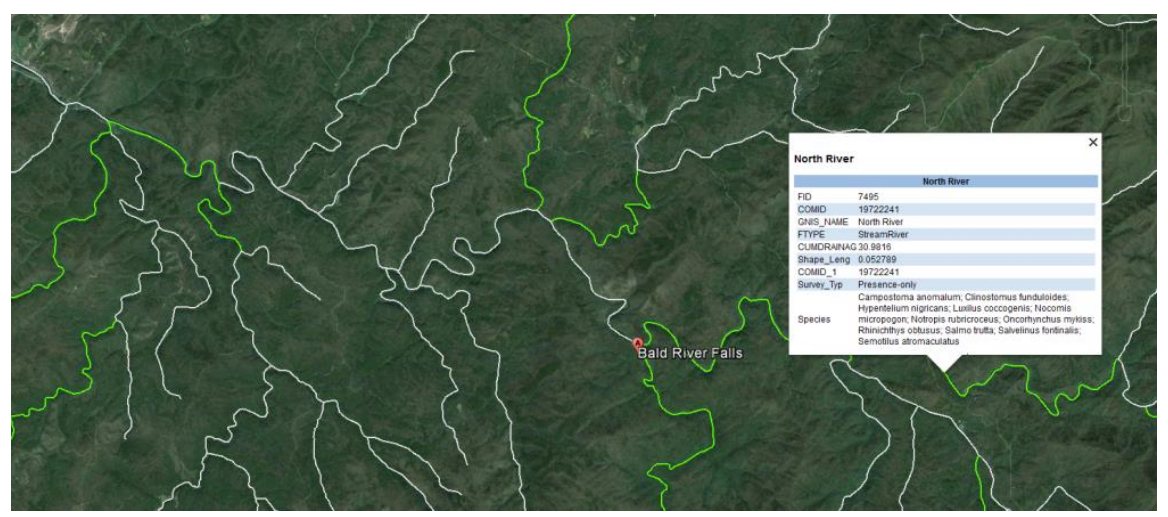

2. Although similar species are found in both rivers, more species have been detected in the Tellico River.

v. Find additional potential reference streams in the region by following the steps above.

e. In the search panel, type "Walters Dam, Clyde, NC" and click "Search". Unclick the box adjacent to the Fish.kmz layer and check the box adjacent to a natural class layer in the "Places" panel.

i. Google Earth will zoom to Walters Dam on the Pigeon River. Notice the white line initiating just to the west of Walters Dam and extending in the northwest direction. Click on the line to open the dialogue box. Notice the Feature Type (FType) is a "Pipeline." Similar to Santeetlah Dam, Walters Dam is a diversion project. Follow the pipeline down to the powerplant several miles downstream.

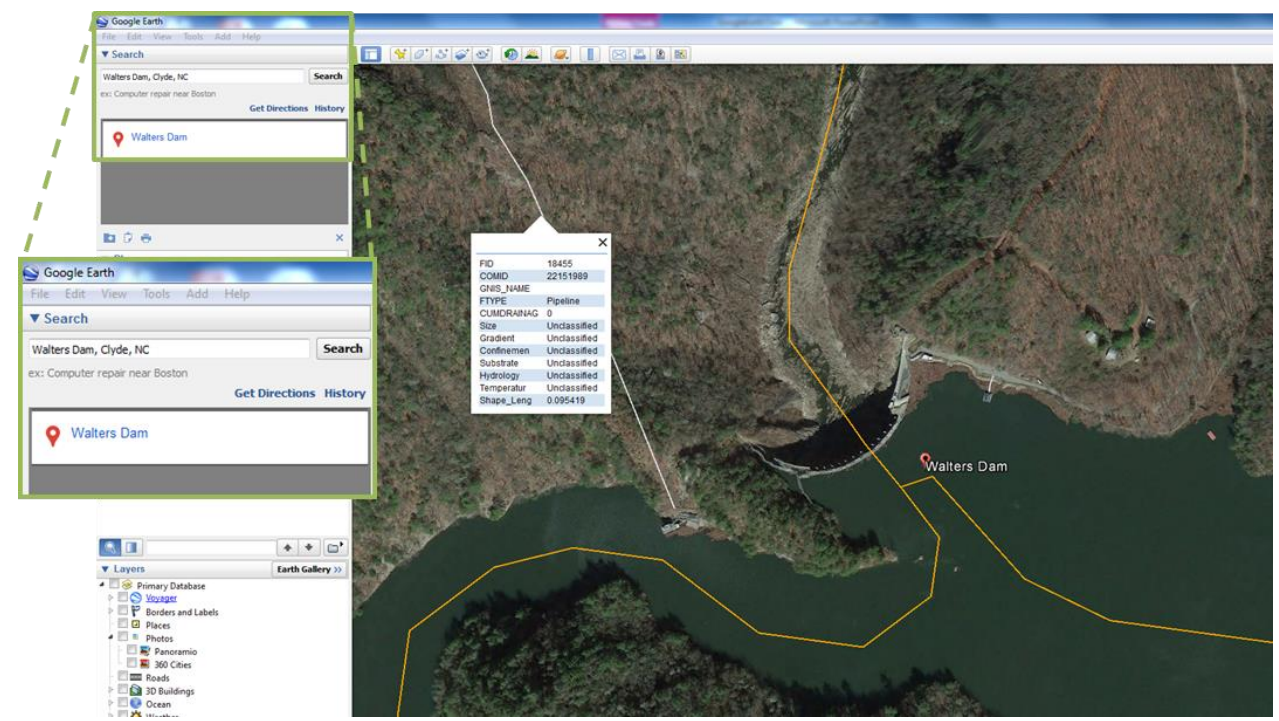


ii. Zoom back to Walters Dam and click on a segment downstream of the dam. The natural stream class for the Pigeon River is similar to the Cheoah River except that the temperature class is a Cold-Cool system.

iii. Unlick the box for the

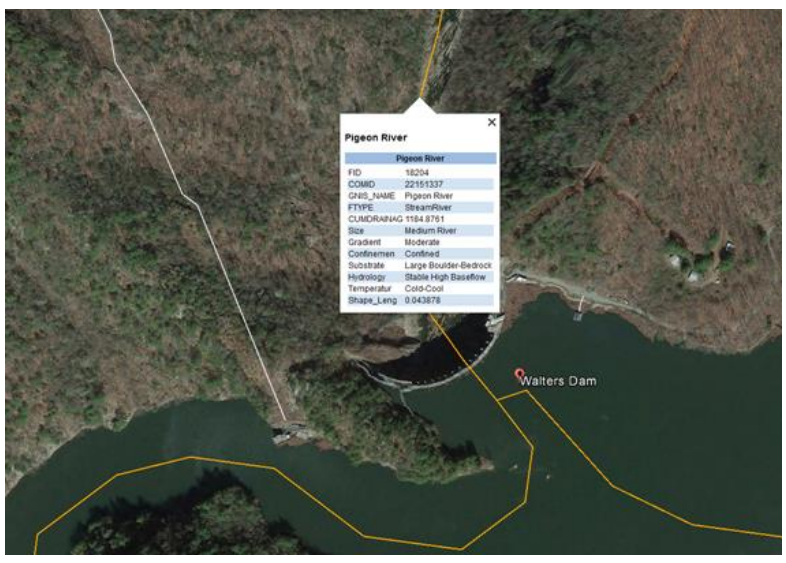
natural class layer and click the box adjacent to the Disturbance.kmz layer.

1. Notice that cumulative upstream dam storage is 30,900 acre feet, almost seven times lower than that of the Cheoah River below Santeetlah Dam. Degree of regulation is $4.7 \%$ compared to $>60 \%$ in the Cheoah River.

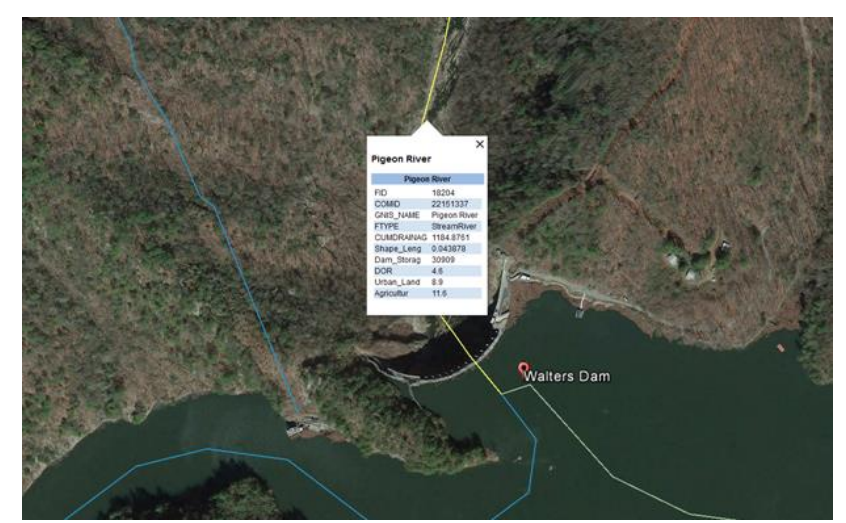

2. It seems the Pigeon is less regulated than the Cheoah. Zoom in to have a closer view of the Pigeon River streambed below Walter Dam. Based on visual observation, it is obvious that the streambed is dewatered more extensively than that in the Cheoah River. Thus, the Pigeon River below Walters Dam may provide a good case study for habitat conditions in the Cheoah River.

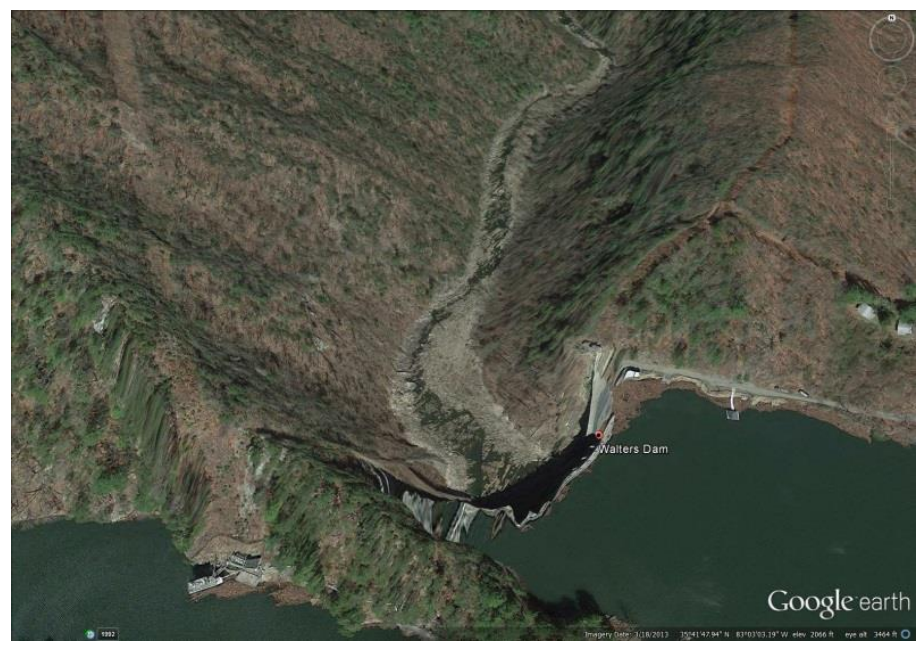


iv. Unclick the box adjacent to the Disturbance.kmz layer and open the Fish.kmz layer.

1. Scan the area and examine the species detected in the Pigeon River and compare to the species list in the Cheoah River.

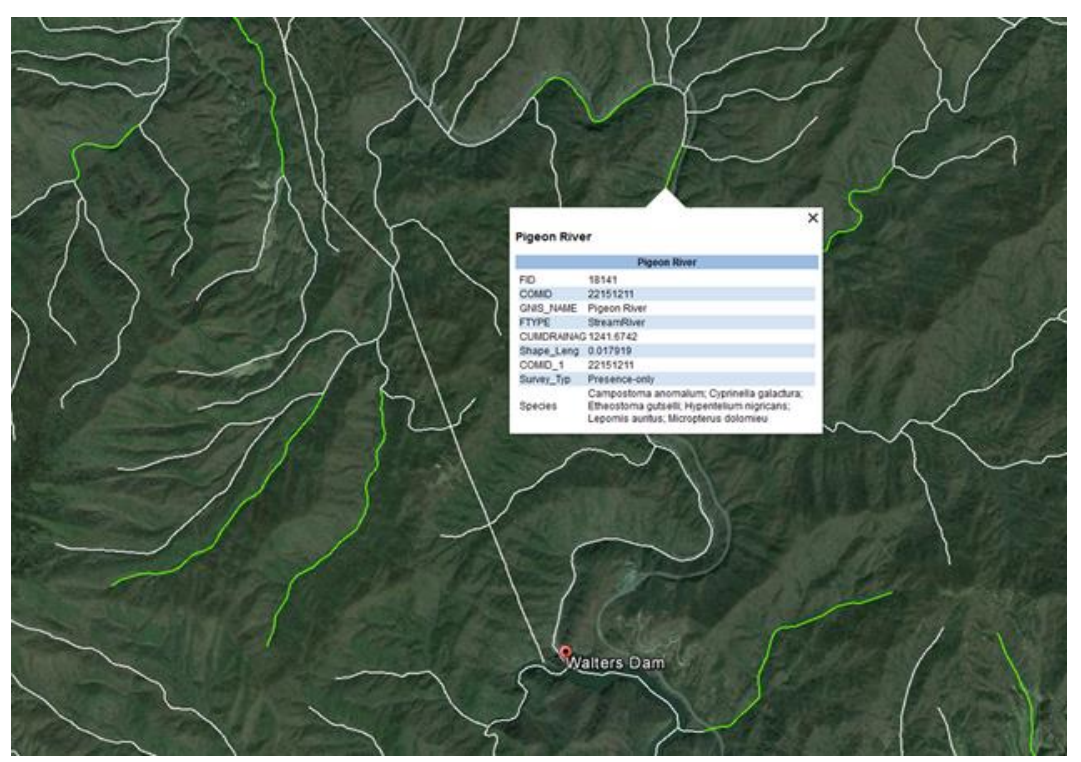

2. Draw some conclusions about potential habitat limitations in both rivers.

v. Find potential additional case studies in the region by following the steps above. 


\section{REFERENCES}

Bednarek, A. T., and Hart, D. D. 2005. Modifying dam operations to restore rivers: ecological responses to Tennessee River dam mitigation. Ecological Applications 15: 997-1008.

Deweber, J. T, and Wagner, T. 2014. A regional neural network ensemble for predicting mean daily river water temperature. Journal of Hydrology 517: 187-200.

Flinders, C. A., and D. D. Hart. 2009. Effects of pulsed flows on nuisance periphyton growths in rivers: A mesocosm study. Rivers Research and Applications 1330: 1320-1330.

Frimpong, E. A., Angermeier, P. L. 2010a. Comparative utility of selected frameworks for regionalizing fish-based bioassessments across the United States. Transactions of the American Fisheries Society 139: $1872-1895$.

Hartwig, J. J. 1998. Recreational use, social and economic characteristics of the Smith River and Philpott Reservoir fisheries, Virginia. M.S. thesis, Virginia Polytechnic Institute and State University, Blacksburg, Va.

Hill, R. A., Hawkins, C. P., and Carlisle, D. M. 2013. Predicting thermal reference conditions for USA streams and rivers. Freshwater Science 32, 1: 39-55.

Horton R. E. 1945. Erosional development of streams and their drainagebasins - hydrophysical approach to quantitative morphology. Geological Society of America Bulletin 56: 275-370

Krause, C. W., Newcomb, T. J., and Orth, D. J. (2005). Thermal habitat assessment of alternative flow scenarios in a tailwater fishery. River Research and Applications, 21(6), 581-593.

McManamay, R. A. 2014. Quantifying and generalizing hydrologic responses to dam regulation using a statistical modeling approach. Journal of Hydrology 519: 1278-1296.

McManamay, R. A. Orth, D. J., Dolloff, C. A., Cantrell, M. A. 2010. Gravel addition as a habitat restoration technique for tailwaters. North American Journal of Fisheries Management. 30(5): 12381257.

McManamay, R. A, Bevelhimer, M.S., Frimpong, E. A. Associations among hydrologic classifications and fish traits to support environmental flow standards. In press. Ecohydrology DOI: 10.1002/eco.1517.

McManamay, R. A., Bevelhimer, M. S., Kao S-C. 2014. An updated US hydrologic classification: a tool to stratify analyses in ecohydrology. Ecohydrology 7: 903-926.

McManamay R. A., Orth, D. J., Dolloff, C. A. 2012. Revisiting the homogenization of dammed rivers in the southeastern US. Journal of Hydrology 424-425: 217-237.

McManamay, R. A., Orth, D. J., Dolloff, C. A., Mathews, D. C. 2013. Application of the ELOHA framework to regulated rivers in the upper Tennessee River basin: a case study. Environmental Management 51(6): 1210-1235.

Olivero, A. P., Anderson, M. G. 2008. Northeast Aquatic Habitat Classification System. The Nature Conservancy Eastern Regional Office, Boston, Mass. September 30, 2008. 88 pp. 
Omernik, J. M. 1987. Ecoregions of the conterminous United-States. Annals of the Association of American Geographers 77: 118-125.

Pearsall, S. H., McCrodden, B. J. and Townsend, P. A. 2005. Adaptive management of flows in the lower Roanoke River, North Carolina USA. Environmental Management 35:353-67.

Pennak, R. W. 1971. Toward a classification of lotic habitats. Hydrobiologia 38: 321-334.

Rosgen, D.L. 1994. A classification of natural rivers. Catena 22: 169-199.

Snelder, T.H., Dey, K. L., Leathwick, J. R. 2007. A procedure for making optimal selection of input variables for multivariate environmental classifications. Conservation Biology 21: 365-375.

Sokal, R. R. 1974. Classification - purposes, principles, progress, prospects. Science 185: 1115-1123.

Strahler, A. N. 1957. Quantitative analysis of watershed geomorphology. Transactions of the American Geophysical Union 38: 913-920.

USACE (US Army Corps of Engineers). 2012. Environmental Assessment for the Gathright Dam Low Flow Augmentation Project, Alleghany County, Virginia. USACE Norfolk District, Norfolk, Va. 89 pp. Available at:

http://www.nao.usace.army.mil/Portals/31/docs/regulatory/publicnotices/2012/Dec/GathrightDamLo wFlowAugmentation EA.pdf

Wolock, D. M., Winter, T. C., McMahon, G. 2004. Delineation and evaluation of hydrologic landscape regions in the United States using geographic information system tools and multivariate statistical analyses. Environmental Management 34: S71-S88. 